\title{
Das Würzburger Sondersendrecht für christianisierte Slawen und sonstige Nichtfranken \\ Ein Rechtstext aus der Zeit König Konrads I. (918?) Einführung, Edition und deutsche Übersetzung ${ }^{*}$
}

\section{Hans-Dietrich Kahl}

Briefly dealt with in the 2004 Studia Mythologica 7, this source had been now published and supplemented with the translation from Latin to German. Believed to have originated during the period of King Konrad I (918 ?), the text had obviously been adopted in Würzburg, and in the presence of the ruler. Together with the Tribur Synod of 859 and the Hohenaltheim Synod of 916 it represents the tendency from the late period of the Carolingian rule to obtain, by means of the Church, the power in the area that had a large share of the Slavic population. Particularly emphasized is the trebo ceremony. Content comparisons with other ecclesiastic legal texts are clearly evident.

\section{Übersicht}

Einführung: I. Einordnungsprobleme S. (39-41). - II. Würzburger Provenienz? S. (41-43). - III. Eingrenzung der Datierungsmöglichkeiten S. (43-45).- IV. Motivgeschichtliche Einordnung S. (46-50). - V. Synodalschluß zur Herrschaftssicherung aus der Spätzeit König Konrads I.? S. (50-56). - VI. Ausklang S. (56-57). - Textedition und Verdeutschung (S. (58-63).

\section{Einführung}

Der Quellentext, der hier erneut vorgelegt wird, ist seit gut 150 Jahren bekannt. Er gibt konzentriert wie selten Einblick in die Bevölkerungs- und Herrschaftsverhältnisse, in die religions- und sozialgeschichtliche Situation des Bestimmungsgebietes, doch herangezogen wurde er selten. Vor allem Zuweisungsschwierigkeiten legten sich in den Weg. Kürzlich ließen sie sich, wie es scheint, beheben, und es wurde möglich, ihn in dieser Zeitschrift ausführlich zu würdigen, wenn auch nicht erschöpfend ${ }^{1}$. Das weckte den Wunsch, über Einzelzitate hinaus auch den vollen Wortlaut wieder leichter verfügbar zu haben, der 1907 zuletzt vollständig gedruckt worden war, und das als Anhang zu einer schwer zugänglich gewordenen Spezialmonographie ${ }^{2}$. Schließlich empfangen Details Licht auch

\footnotetext{
* Vorliegender Beitrag gibt mit freundlichem Einverständnis der Schriftleitung einen Wiederabdruck aus dem Archiv für die Geschichte von Oberfranken 87, Bayreuth 2007, S. 7-32.

1 H.-D. Kahl, Das erloschene Slawentum des Obermaingebietes und sein vorchristlicher Opfer - brauch (trebo) im Spiegel eines mutmaßlich würzburgischen Synodalbeschlusses aus dem 10. Jh., in: SMS 7 (2004), S. 11-41, danach hier zitiert; Wiederabdruck im Archiv für Geschichte von Oberfranken 86 (2006), S. 7-40, durch eine Karte zum Mainslawenproblem ergänzt.

2 Bei A. M. Koeniger, Die Sendgerichte in Deutschland I, München 1907, S. 194-196.
} 
von dem Gesamtzusammenhang her, der sie einschließt. Diesem Wunsch wird hiermit entsprochen. Aus Raumgründen wird möglichst wenig wiederholt, was bereits die vorige Abhandlung ausbreitet. Neu aufgerollt werden muß jedoch das Problem der Da tie - rung und historischen Einordnung, zu dem ergänzende Gesichtspunkte aufgetaucht sind.

\section{I.}

Die Überlieferung des Textes, der provisorisch als T bezeichnet sei, stellt keine Originalausfertigung zur Verfügung. Sie unterschlägt, wann, wo und durch wen T zustandekam, und beschränkt sich auf das Inhaltliche. Der Form nach handelt es sich um so etwas wie einen Synodalschluß, der Lebensverhältnisse im Bestimmungsgebiet den Normen der damaligen Kirche anpassen soll, und zwar mit den Mitteln des geistlichen Gerichts der Zeit, des sog. Send ${ }^{3}$. Vorausgesetzt wird ein gefestigtes Niederkirchenwesen unter geordneten Herrschaftsverhältnissen, die im eingespielten Zusammenwirken geistlicher und weltlicher Gewalt ein scharfes Durchgreifen möglich machen. Weiteres kann im wesentlichen allein aus dem Text selbst gefolgert werden.

Die wahrscheinlich ältere der beiden Handschriften gehört nach neueren Ergebnissen in die Zeit um $1040^{4}$. Damit ist ein provisorischer Terminus ante quem gegeben.

Sucht man dem einen Terminus a quo gegenüberzustellen, so hat man sich zunächst mit der Tatsache auseinanderzusetzen, daß T im ersten Kapitel hier eingeführter Zählung zwei Partien einschließt, die noch anderweitig überliefert sind und dort Quellenangaben zeigen. Sie erscheinen in einer Canonessammlung, die ein Salzburger Codex umstrittener Herkunft einschließt, gleichfalls aus dem 11. Jh. Das Gegenstück zu I, 1 ist durch Rückverweis auf den vorausgehenden Canon dem Konzil von Tribur zugeschrieben (in Triburiensi concilio); II, 2-3 enthält einige Sätze aus einem erheblich längeren Passus, der dort auf ein Konzil von Rouen zurückgeführt wird (concilio Rodomagensi); dabei läßt der Textvergleich sich lediglich bis zu der Stelle durchführen, an der die Salzburger Fassung abbricht - ob T die gemeinsame Vorlage weiter zitiert oder mit II, 1 selbständiges Formulieren beginnt, ist nicht sicher auszumachen ${ }^{5}$. Gibt das Datierungshinweise? Ein Konzil von Tribur ist wohlbekannt. Es wurde 895 unter König - noch nicht Kaiser - Arnulf im heutigen Trebur (bei Groß-Gerau, Hessen) abgehalten und gehört zu den markantesten Ereignissen von dessen Regierungszeit. Leider liegt es mit der Überlieferung im argen, und wir können noch nicht einmal auf eine moderne Ausgabe zurückgreifen. Es gibt zahlreiche Extravaganten, und ihre Authentizität ist teilweise umstritten; ausgerechnet der hier wichtige Canon zählt zu denen, die nicht allgemein anerkannt sind ${ }^{6}$. Das Konzil von Rouen aber gehört zu den

${ }^{3}$ H. Zapp, Send, in: Lexikon des Mittelalters (= LMA) VIII (1995), Sp. 1747 f. m. Lit.

4 Zum flg.: Kahl, S. 18 ff.

5 (G.) Phillips, der Codex Salisburgensis S. Petri IX. 32, in: Sitzungsber. d. Akad. d. Wiss. Wien, phil.-hist. Kl. 44 (1863), S. 469, 471 f. u. 501-503. Zur Handschrift noch: P. Fournier - G. Le Bras, Histoire des collections canoniques en occident etc. I, Paris 1931, S. 305-310 ; R. Kottje, Eine Salzburger Handschr. aus Köln, in: Rhein. Vierteljahrsbll. 28 (1963), S. 286-290; H. Fuhr - mann, Einfluß u. Verbreitung d. pseudoisidor. Fälschungen III, München 1974, S. 706, Anm. 257, vgl. S. 683 ff., 707, 716 Anm. 289 sowie S 749 samt Anmerkung von R. Kottje, ebd., S. 629, Anm. 6.

6 Synode von Tribur: W. Hartmann, Die Synoden der Karolingerzeit im Frankenreich u. in Italien, Paderborn 1989, bes. S. 7 f., 10., 22 f., 25, 299, 367-371, 481 u. ö. (Register S. 523), dazu H. Wolter, Die Synoden im Reichsgebiet und in Reichsitalien von 916 bis 1056, Paderborn 1988, Register, S. 517, über die Nachwirkung. Ausgabe: V. Krause, MGH Cap. II, S. 196-249, dazu Ders., Die Akten der Triburer Synode 895, in Neues Archiv 17 (1892), S. 51 ff., sowie ebd., 18 (1893), S. 411 ff., mit Kritik von E. Seckel, ebd. S. 36-409; dazu H. 
Cruces der Forschung. Es wird mehrfach in ähn- licher Weise zitiert, besonders bei Regino von Prüm ( $†$ 915); wir besitzen jedoch keine vollständige, nicht einmal eine größere zusammenhängende Textüberlieferung - selbst für die behaupteten Exzerpte ist unklar, ob wenigstens hinter ihnen noch ein greifbarer Gesamttext gestanden hat oder auch nur ein Zitat von Zitiertem. Einzig bezeugt ist für diesen Tagungsort eine Synode von 650 . Mit ihr läßt sich rein von der Problemstellung her keins der bekannten Bruchstücke in Verbindung bringen - sie würden am ehesten in die Zeit um 878/80 passen. Es ist nicht einmal sicher auszuschließen, daß es nach 650 gar keine Synode von Rouen mehr gegeben hat und die Angaben auf Erfindung beruhen7. Der Passus, um den es hier geht, taucht bei Regino nicht auf, so daß selbst die Abfassungszeit seines Handbuchs (um 906) uns nicht weiterhilft. Kurz: Uns bleibt einstweilen nichts, als das Suchen nach Hinweisen aus solcher Richtung einzustellen ${ }^{8}$. Wir sehen uns allein auf das angewiesen, was T vom Inhalt her an Indizien zur Verfügung stellt.

II.

Das Rubrum weist auf eine Region unter fest etablierter fränkischer Herrschaft mit ethnisch gemischter Bevölkerung. Slawen stellen einen so bedeutenden Anteil, daß sie als einzige namentlich hervorgehoben werden; was für Elemente sonst im Lande lebten, bleibt ungesagt - T spricht lediglich von Sclavi vel ceterae nationes (in Mehrzahl). Den namentlich Genannten kam also keine der mitbeteiligten Gruppen an Zahl und Bedeutung gleich. Die Urheber des Textes geben dabei zu erkennen, daß sie deutschsprachig waren - die Rede ist von Hügeln, quos dicimus [...] hougir (II, 1). Die erste Person Pluralis bezeichnet also ein althochdeutsches Wort als eigensprachlich, und zwar im Gegensatz $\mathrm{zu}$ einem anderen, slawischen, quod trebo dicitur (ebd.), in unpersönlicher Passivform. Hougir ist Mehrzahl zu houc „Hügel“ und hat zusätzlichen Zeugniswert: Es zeigt, daß T nur im Maingebiet oder weiter nördlich entstanden sein kann, denn weiter nach Süden

Hoffmann - R. Pokorny, Das Dekret des Bischofs Burchard von Worms. Textstufen - Frühe Verbreitung Vorlagen, München 1991, S. 69 f. m. Anm. 25, und vor allem R. Pokorny, Die drei Versionen der Triburer Synodalakten von 895, in Deutsches Arch. 48 (1992), bes. S. 432-466 und 481-385, mit teilweiser Kritik von W. Hartmann, Kaiser Arnolf und die Kirche, bei F. Fuchs - P. Schmid (Hg.), Kaiser Arnolf, München 2002, S. 238 f., 241 f., 245-251 m. weiterer Lit. - Zum oben behandelten Sonderkanon: Ae. L. Richter - R. Dove -W. Kahl, Lehrbuch d. kath. u. ev. Kirchenrechts, 8. Aufl. Leipzig 1886, S. 143 Anm. 4; Krause, NA 17 (1892), S. 326; Ders., MGH Cap. II, S. 197 f. mit Tabelle II, 10; Koeniger, Sendgerichte I, S. 52 m. Anm. 2, S. 197 f., vgl. 202 f. - S. nach - stehend Anm. 8.

7 E. Seckel, Die ältesten Canones von Rouen, in: Histor. Aufsätze, Karl Zeumer dargebracht, Weimar 1910, S. 611-635; Hartmann, Synoden, S. 385 f. und 435, vgl. 478 u. 481: O. Pontal, Die Synoden im Merowingerreich, Paderborn 1986, S. 203 f. m. Anm. 20. Zum fraglichen Einzelkanon: Phillips, S. 501-503; A. M. Koeniger, Beiträge zu den fränkischen Kapitularien und Synoden, in: Arch. f. kath. Kirchenrecht 87 (1907), S. 395 f. m. Anm. 3; Ders., Sendgerichte I, S. 196-198; Seckel, Rouen, S. 629 m. Anm. 3; E. Mayer, Das sog. Sendweistum der Mainund Rednitzwenden usw., in: Zschr. f. Bayer. Landesgesch. 6 (1933), S. 3-15. passim (aus: Arch. d. Hist. Vereins f. Unterfranken 68, 1929; mit verfehlter Grundthese, gegen die bereits A. M. Koeniger, Art. Slawen-Sendrecht, in: Lex. f. Theologie u. Kirche IX, 1937, S. 624); Hartmann, Synoden, S. 466; Ders., in MGH Concil. III (1984), S. 131 Anm. 8. - Fernzuhalten sind die sog. Capitula Rotomagensia (MGH Cap. Episc. III, 1984, S. 367-371). - Vgl. flg. Anm.

${ }^{8}$ Die theoretische Möglichkeit, daß die fraglichen Partien der Salzburger Sammlung nicht Quelle für T, sondern umgekehrt aus T entlehnt sind, wird verschiedentlich erörtert; große Wahrscheinlichkeit vermag ich ihr nicht beizumessen. Vgl. Krause, NA 17 (1892), S. 326 sowie MG Cap.. II, S. 206, Nr. 5; Koeniger, Archiv 1907, wie vor. Anm.; P. Hinschius, System des kath. Kirchenrechts V/1, Berlin 1893, S. 430 f. Anm. 6. 
hin wurde der Ausdruck durch einen anderen abgelöst ${ }^{9}$. Dazu paßt, daß die Überlieferung von T sich auf Kathedralsitze des Erzbistums Mainz konzentriert, nämlich Eichstätt, dessen Zuständigkeiten slawische Bevölkerungsteile einschlossen, andererseits aber das merkwürdig abgelegene Konstanz, im deutschsprachigen Binnenland, an einer Stelle, wo nicht slawische Sprachprobleme akut waren, sondern allenfalls solche rätoromanischer Art. Mainz selbst ist, wie all seine übrigen Suffragane, unbeteiligt, obwohl es im Ostteil der unmittelbaren Erzdiözese gleichfalls slawische Bevölkerung zu betreuen hatte, deren Bekehrungsstand noch 1074 als reichlich mangelhaft gekennzeichnet wird ${ }^{10}$. Schwer ist der Eindruck abzuweisen, daß die Überlieferung von T auf Zufällen beruht, die von akutem Bedarf an entsprechenden Regelungen unabhängig sind, doch wird man den Bereich der Mainzer Kirchenprovinz nicht verlassen, solange sich dafür keine besonderen Gründe ergeben.

Ältere Forschung hat teilweise Eichstätt als Entstehungsort in Anspruch genommen. Das hat zwei Beobachtungen gegen sich. T ist in beiden Überlieferungen als Extravagante der Dekretaliensammlung Burkhards von Worms hinzugefügt. Dabei erscheint der $\mathrm{Zu}$ satz in der Eichstätter Überlieferung ebensowenig wie in derjenigen aus Konstanz als ein selbständiger Nachtrag auf zufällig freigebliebenen Spalten, wie sonst so oft. Beide Male tritt $\mathrm{T}$ an der gleichen Stelle auf, die vom thematischen Zusammenhang durchaus nicht prädestiniert erscheint, gerade ihn aufzunehmen; die Hand, die ihn schrieb, ist in beiden Fällen identisch mit derjenigen, von der die vorausgehenden Textteile stammen, im Eich - stätter Fall auch noch die unmittelbar anschließenden. Beide Schreiber müssen den Passus also bereits in ihrer Vorlage vorgefunden haben, die einstweilen weder hier noch dort nachgewiesen werden kann. ${ }^{11}$ Im übrigen liegt Eichstätt ebenso wie Konstanz außerhalb des bekannten Verbreitungsgebietes von houc. Um so mehr zieht das benachbarte Würz - burg den Blick an, unmittelbar am Main gelegen, ein altes Zentrum der Überlieferung dieses Ausdrucks, den sein Stift Haug bis heute im Namen bewahrt. Prüfen wir, ob das, was T sonst noch an Bedingungen stellt, dort ebenfalls als erfüllt gelten kann.

Gleich für die erste, schon geschilderte Voraussetzung ist dies der Fall. Was sich T zur gegebenen Herrschafts- und Bevölkerungssituation entnehmen läßt, stimmt für den Würz - burger Diözesanbereich mindestens für das 8.-10. oder 11. Jh. ${ }^{12}$ Daß die Bischöfe sich der Christianisierung der die Ostteile besiedelnden Slawen annahmen, war ein Anliegen schon Karls d. Gr. gewesen, und seitdem hatten sie sich mit bemerkenswerter Beharrlichkeit immer wieder um Erneuerung der Privilegien bemüht, die sie dazu erhalten hatten, zuletzt 889. ${ }^{13}$ Erst 1007, mit Abzweigung des neuen Bamberger Bistums, wurde ihnen diese Auf - gabe abgenommen. Eine Synode vor diesem Jahr, vermutlich in größerem Abstand, die das Würzburger Bistum betraf, ist als Urheberin der in T wiedergegebenen Beschlüsse insofern durchaus in Betracht zu ziehen, und wir hätten damit, wenn diese Zuweisung sich bestätigt, zugleich einen weiteren Hinweis zum Terminus ante quem. Von den slawischen Mundarten des älteren Würzburger Sprengels ist nur wenig erkennbar.

\footnotetext{
9 Kahl, S. 19 f. m. Anm. 46. Vgl. noch unten Anm. 76.

${ }^{10}$ O. Dobenecker, Regesta Diplomatica necnon Epistolaria Historiae Thuringiae I, Jena 1895, Nr. 911 f. (S. 191

f.), dazu H. Leo, Untersuchungen zur Besiedlung und Wirtschaftsgesch. d. thüring. Osterlandes, Leipzig 1900,

S. 66 f.; E. schwarz, Sprache u. Siedlung in Nordostbayern, Nürnberg 1960, S. 362.

${ }^{11} \mathrm{Zu}$ alledem, auch zum flg., Kahl, bes. S. 19-21. Vgl. Abb. unten S. 57 sowie Anm. „u“ zur anschließenden Textedition, II, 2.

${ }^{12}$ Kahl, bes. S. $21,25-30$ u. 31 f. Vgl. unten Anm. 58

${ }^{13}$ Übersicht: Schwarz, S. 357
} 
Daß der Wort - stamm des Ausdrucks, den T als trebo wiedergibt, dort bekannt war, ist durch Ortsnamen bezeugt. ${ }^{14}$

III.

Das Rubrum deutet auf ungebrochene Geltung des karolingerzeitlichen Persona litäts - prinzips im Recht: Es wird kaum eine Quelle geben, die einem slawischen Bevölkerungs - teil im Frankenreich und seinen Nachfolgestaaten dermaßen eindeutig bescheinigt, daß er den Status einer „nach eigenem Recht lebenden Volksgruppe besitzt“ ${ }^{15}$ Die Bevölkerung des Bezugsgebietes von T insgesamt bot offenbar rechtlich, und das heißt bis zu einem gewissen Grade auch: ethnisch, ein ziemlich buntes Bild. Franken spielten eine gewichtige Rolle. Darüber hinaus erfahren wir Näheres nicht, doch die Sozialstruktur wird beleuchtet, mit seltener Schärfe und Konzentration (II, 5-7). Vordringlich genannt wird der Fronbauer auf Staats- bzw. Königsland (fiscalinus colonus). Er stellte wohl den größten Anteil. Es gab auch freie Eigentümer (in suo [...] praedio); andere waren Hintersassen eines solchen (in [...] alterius praedio), der für sie dann der Herr (dominus) war. Es ist nicht zu leugnen, daß all das sich gut zu den Vorstellungen fügt, die wir für die Karo - linger zeit und darüber hinaus mit dem östlichen, dem heutigen engeren Franken verbinden. Leider erfahren wir nicht, wie die Slawen sich auf diese verschiedenen Schichten verteilten - ob sie an ihnen allen Anteil hatten oder nicht. Was in der Aufzählung fehlt, sind Hörige auf Kirchengut. Daß dort im Sinn der getroffenen Verfügungen durchzugreifen war, mag gar zu selbstverständlich gewesen sein. In den sehr detaillierten Ausführungs - bestimmungen zeigt $\mathrm{T}$ - und auch das weist in eine frühere Phase - eine so enge $\mathrm{Zu}$ sammenarbeit geistlicher und weltlicher Gewalt an ausgesprochen kirchlichen Zielen, wie man sie sich schon für die Periode der Sachsenkaiser nicht mehr recht vorstellen kann. Sie entspricht bestimmten Forderungen des römischen Kaiserrechts, deren Kenntnis sich in der Karolingerzeit und kurz danach im Frankenreich bemerkenswert weit verbreitet zeigt. ${ }^{16}$ In den Synoden von Tribur (895) und Hohenaltheim (916) wurde sie besonders intensiv praktiziert. T erwähnt in diesem Zusammenhang zwei weltliche Herrschafts - träger, bezeichnet als centurio und als $d u x$ (II, 2 u. 6). Hinter dem ersten Ausdruck verbirgt sich ein untergeordneter Amtsträger, dessen Funktion früh im Hochmittelalter erlosch, ahd. hunno, sonst häufiger durch centenarius wiedergegeben, in der Fachliteratur früher vielfach als „Zentgraf“ bezeichnet. In Mainfranken war er schon nach dem Aus - weis von Ortsnamen bekannt ${ }^{17}$ und kann folglich das sich abzeichnende Bild nicht stören. Was den $d u x$ angeht, so hat seine Bedeutung sich mehrfach gewandelt. Ungefähr bis zur Mitte des

\footnotetext{
${ }^{14}$ Kahl, S. $21 \mathrm{f}$.

${ }^{15}$ Vgl. H. Liermann, Zur mittelalterl. Rechtsgesch. Frankens, in: Jahrb. f. fränk. Landesforsch. 5 (1939), S. 2 m. Anm. 4.

${ }^{16}$ Dazu W. Hartmann, Der Bischof als Richter, in: Röm. Hist. Mitteil. 28 (1986), S. 104 f. m. Anm. 4-5.

${ }^{17}$ G. Gudian, Handwörterbuch z. dtsch. Rechtsgesch. I (1978), S. 603-606, s. v. centenarius, passim; A. Kroeschell, ebd. II (1978), S. 271-275, s. v. Hundertschaft, passim; Ders., LMA V (1991), Sl. 214 f., s. v. Hundert; vgl. D. Claude, centenarius, ebd. II (1986), Sp. 1620 f.; Th. Andersson, Reallex. d. Germ. Altertumskunde XV (2000), S. 235 ff. s. v. Hundare, passim. - Schon R. Dove, Das von mir sg. Sendrecht der Main- und Rednitzwenden, in: Zschr. f. Kirchen - recht 4 (1864), S. 168 zieht den centurio im Rahmen damaliger Möglichkeiten als Datierungs - merkmal heran. Seine Arbeit insgesamt, die erste ernstzunehmende, die sich mit T befaßt, ist ein klassisches Beispiel für eine alte Untersuchung, die bei näherem Zusehen auch bei neueren Argumenten gegen gelegentlichen Widerspruch meist noch immer recht behält.
} 
10. Jh. bezeichnet er einen weltlichen Machthaber herausgehobener Stellung, ohne daß sie verfassungsrechtlich fixiert ist - eine Art Übergraf, der z. B. mehrere Grafschaften vereinigt, doch ist $d u x$ dafür noch kein festgelegter Be griff, sondern wechselt mit marchio und auch noch mit comes. Unter den Ottonen dringt früh die Bedeutung eines Amtsherzogs vor, den es vorher nicht gegeben hatte, vom Herrscher eingesetzt und ihm unmittelbar unterstehend, später nochmals abgelöst durch die eines hohen, erblichen Adelsranges. Die mittlere dieser Bedeutungen kommt für Ostfranken nicht in Betracht, denn dieses Gebiet blieb, wie gegen ältere Ansicht längst durchgedrungen ist, das Königsland schlechthin, ohne jeden Amtsherzog. Der $d u x$-Titel, den der Bischof von Würzburg im 12. Jh. ausnahmsweise erlangte, kann in T nicht gemeint sein, denn der so Bezeichnete hat Aufgaben wahrzunehmen, für die geistliche Herren nicht in Betracht kamen. Auch der „Herzog von Rotenburg“, auf den Konrad III. vor seiner Königs er he - bung als Herzogssohn Anspruch erhob, bleibt hier fern. Wenn $\mathrm{T}$ in diese Geschichts - landschaft gehört, kann einzig die erste der drei Bedeutungen gemeint sein. Tatsächlich treffen zwischen dem Ende der Babenberger Fehde (906) bis zur Schlacht von Andernach (939) die entsprechenden Voraussetzungen für zwei Brüder aus dem Hause der Konra - diner zu, die damals in dieser Region unangefochten an der Spitze standen, zunächst für Konrad, der dann von 911-918 als erster seines Namens König war, dann für dessen Bruder Eberhard, der in jener Schlacht fiel. ${ }^{18} \mathrm{~T}$ bringt den $d u x$ ohne zugehörigen Perso - nen namen, einfach als Rangbezeichnung, und böte damit einen verhältnismäßig frühen Beleg für diese Verwendung. Doch gerade im dortigen Zusammenhang ist die Aufnahme des Ausdrucks verständlich. Ein Instanzenzug war zu umreißen, in den der comes einbezogen war; ein Ausdruck, der eindeutig genug einen Höherstehenden benannte, war unentbehrlich. Mainfranken ist auch von hier aus als Heimat von T nicht auszuschließen. Achten wir noch auf die Stellung der Quelle in der Geschichte des Sendgerichtswesens. Die maßgebliche Versammlung wird als placitum episcopi sive archipresbyteri bezeichnet (II, 1). Je nachdem, wie man diesen Beschluß datiert, ist er damit die erste oder eine der ersten Quellen, die die Abhaltung des Sends nicht ausschließlich dem Bischof selbst vorbehalten, sondern die Möglichkeit einer Delegation voraussetzen. ${ }^{19}$ Das spiegelt ein fortgeschritteneres Entwicklungsstadium. Auch das Institut der Send- oder Rügezeugen, das T in I, 2-3 mit jenen angeblichen Formulierungen aus Rouen anspricht, zeigt sich verhältnismäßig weit ausgebildet. ${ }^{20} \mathrm{Im}$ übrigen ist unverkennbar allein von Verfahren gegen Laien die Rede - Visitation von Klerikern klingt nirgends an. Beide sind also offenbar bereits wie selbstverständlich nach Zeitpunkt und Schauplatz getrennt. ${ }^{21}$ Noch nicht angedeutet ist die Absonderung Adeliger aus der Menge der Sendpflichtigen, die sich, regional verschieden, im fortschreitenden Hochmittelalter durchsetzt, doch findet sich eine Art Vorstufe dazu in einer Begünstigung des fränkischen Reichsvolks, auf die zurückzukommen ist.

Inhaltlich fällt der starke Akzent auf, den T auf die Bekämpfung von Relikten vorchristlichen Kultbrauchs legt, und zwar nicht als abstrakt-allgemeines Verbot, sondern

\footnotetext{
${ }^{18}$ Kahl, S. 18 f. m. Anm. 41; aus genannter Lit. hervorzuheben: H. W. Goetz, „Dux“ und „Ducatus“. Begriffsund verfassungsgeschichtliche Untersuchungen. Bochum 1977; über die Konradiner bes. S. 339. - Vgl. unten Anm. 43.

${ }^{19}$ Vgl. A. Hauck, Send/Sendgericht, in: Realenzyklopädie für protestantische Theologie und Kirche, 3. Aufl. XVIII (1906), S. 213; Koeniger, Sendgericht I, S. 80, dazu 102 ff.

${ }^{20}$ Dove, S. 112; Koeniger, Sendger. I, S. 197, vgl. 52.

${ }^{21}$ Hauck, S. 211.
} 
in ganz konkreter Zuspitzung auf benannte Bräuche des Bestimmungsgebietes, wie sie in dieser Bestimmtheit ungewöhnlich ist (II,1). Bonifatius hatte zur Unterbindung von „Heideleien“ (paganiae) im „Volke Gottes“, ohne sie zu präzisieren, ein Zusammen wirken von Bischöfen und Grafen angestrebt, doch in der erhaltenen Hinterlassenschaft karolingerzeit- licher Synoden weicht dieses Moment auffällig zurück. ${ }^{22}$ Ein gemeinsames Vorgehen beider Gewalten im Verfolg kirchlicher Ziele tritt stärker erst wieder in den genannten Synoden von Tribur (895) und Hohenaltheim (916) zutage, doch auch dann noch zunächst in anderen Themenbereichen. ${ }^{23}$ Diese Synoden verfolgten Probleme, die im ganzen Reich akut waren. Vor Ort lag es nahe, auch Aufgaben einzubeziehen, die dabei abseits liegengeblieben waren, sofern sie sich in hoher Dringlichkeit stellten, stärker als in anderen Gebieten. T spiegelt einen Geist, der so stark dem jener beiden Synoden entspricht, daß man sich trotz abweichenden Gegenstandes schwer entschließen wird, die Fixierung weit von diesen beiden Höhepunkten reichskirchlicher Bestrebungen abzurücken, und zugleich warnt das inhaltliche Moment, die Entstehungszeit tiefer ins 9. Jh. zurückzudatieren.

Das vorgesehene Sühneverfahren, von Beugungsstrafen beherrscht, weist in die gleiche Richtung. Es sieht für den Fall hartnäckiger Unbußfertigkeit, die die Exkommuni ka - tion mißachtet, Repressalien aus weltlicher Rechtsgewohnheit vor, und sie sollen mit erstaunlicher Drastik ein- und durchgesetzt werden. Auch dafür ist T, je nachdem, die älteste oder eine der ältesten Quellen. ${ }^{24}$ Dabei begnügt der nach eigener Aussage kirchliche Text (II, 5: decretum est ab ecclesia) sich nicht mit entehrenden Leibesstrafen an der Person, wie sie sonstigem Sendrecht nicht fremd sind (Prügeln, Haarschur u. dgl.). Es sieht Maßnahmen vor, die in eine ganz andere Dimension vorstoßen, wie Pfän dung von Vermögenswerten (II, 3-4), schließlich Güterkonfiskation und Exilierung (II, 5: $a b$ ecclesia exclusum humana priuari communione; II, 7: expulsus; infiscentur substantiae). Das bedeutet Eingriffe in das Sippeneigentum, die womöglich auch Unschuldige in Mitleidenschaft ziehen. Dergleichen sind Vollzüge, die ein Kleriker allein gar nicht durchzuführen vermag. Eine kirchliche Stelle verfügt also über weltliche Herrschaftsträger mit.

Die Entwicklungslinie, in die T damit einrückt, findet auffällig wenig Beachtung. ${ }^{25}$ Es ist darum erforderlich, etwas weiter auszuholen, damit die Stellung der Quelle im Gesamtzusammenhang deutlicher wird. Diese Linie beginnt in der Karolingerzeit, Frucht ihres neuartigen Denkens über die Verantwortung der Herrschenden für Aufgaben kirchlichen Ursprungs, doch geradlinig verläuft sie von dort aus keineswegs. Versuchen wir, sie wenigstens zu skizzieren.

\footnotetext{
${ }^{22}$ Sog. Concilium Germanicum, c. 5, im Anhang zu: Briefe des Bonifatius usw., bearb. v. R. Rau (Ausgew. Quellen z. dtsch. Gesch. d. Mittelalters IVB), Darmstadt 1968, S. 379; Synode von Estiennes, c. 4 (ebd., S. 384); Synode von Soissons, c. 7 (ebd., S. 386); sowie den Indiculus superstitionum et paganiarum (ebd., S. 444-448), jetzt vielseitig beleuchtet von H. Homann - E. Meineke - R. Schmidt-Wiegand, in: Reallex z. germ. Altertumskunde, 2. Aufl. XV (2000), S. 369-384. Dazu Hartmann, Synoden, bes. S. 447 f., vgl. 52 u. 55.

${ }^{23}$ Tribur: oben Anm. 6; Hohenaltheim: MGH Conc. VI/1 (1987), S. 1-40, bes. 19 ff.; dazu Wolter (wie Anm. 6), S. 11-20 (Anm. 6: Quellenlage).

${ }^{24}$ Koeniger, Sendger. I, S. 25 ff., bes. 27, vgl. 62.

${ }^{25}$ Handbücher, aus denen man Orientierung erhofft, setzen mit detaillierteren Informationen hierzu meist erst mit dem Decretum Gratiani oder noch später ein. Selbst das überfachlich angelegte LMA beschränkt sich unter Stichwörtern wie Apostasie, Häresie usw. auf korrekte theologische Definitionen, enthält sich jedoch aller Hinweise zur Strafverfolgung nach kirchlichem und nach weltlichem Recht. Einige Hinweise bei Hinschius V/1 (1895), S. 158 f., vgl. 140 f. 374 ff.; V/2, S. 686 f., vgl. IV, S. 742. Vgl. flg. Anm.
} 
Die Kombination von Verbannung und Güterkonfiskation für hartnäckigen Widerstand gegen kirchliche Normansprüche setzt Mitte 8. Jh. ein, wobei Exilierung als Schlußpunkt nicht unbedingt auf Ausweisung aus dem Heimatgebiet hinausläuft - sie kann auch Klosterhaft bedeuten, auch Anweisung eines bestimmten Aufenthaltsortes (z. B. Iso lie - rung auf einer Insel), auch gefänglichen Gewahrsam und ähnliches mehr. ${ }^{26}$ Schon unter Pippin I. findet sich die Verbindung von Enteignung und Exil für Exkommunizierte, die nicht dazu gebracht werden können, Kontakte mit Christen von sich aus zu meiden, und bei Karl d. Gr. erscheint dieses Strafmaß in schrittweiser Verschärfung der Strafen gegen Zehntverweigerer, doch zu konsequentem Einsatz kommt es noch nicht - man entschied noch spontan, ohne Systematik. ${ }^{27}$ Die barbarische Härte mit zahllosen Todesstrafen, zu der dieser Herrscher sich unter dem Eindruck seiner Mißerfolge gegen die Sachsen hinreißen ließ, ist nur zu gut bekannt. ${ }^{28}$ Kritik blieb nicht aus; ihre Frucht war die grundsätzliche Neubesinnung über den rechten missionarischen Ansatz am Auftakt der Awaren - mission, beim sog. Donaukonzil (conventus episcoporum ad ripas Danubii) von 796, zu dessen Grundsätzen uns jedoch weitgehend Einblick in die praktische Umsetzung fehlt. ${ }^{29}$ Das auffällige Zurücktreten von Maßnahmen gegen „Heideleien“ im folgenden Jahrhundert könnte vielleicht eine weitere Reaktion auf die Maßlosigkeiten Karls gewesen sein. Kaiser Lothar I. hat in den Bruderkriegen nach dem Tode Ludwigs d. Fr. offenbar den Sachsen das Praktizieren ihres alten Glaubens freigestellt und nur Verfolgung derer unterbunden, die Christen zu bleiben wünschten. ${ }^{30}$ Sein Hauptmotiv dürfte politisch gewesen sein: Er wollte sie als Bundesgenossen gewinnen. Doch zur Rechtfertigung genügte das nicht. Hat er geltend gemacht, daß erzwungene Scheinbekehrungen im Grunde fruchtlos sind und daß Entscheidungsfreiheit zumindest für später wirksamer zum Übertritt motivieren kann? Das Strafgericht Ludwigs II. war nochmals überaus hart, aber vielleicht stärker wegen des Aufstandes der „Stellinga“ als aus religionspolitischen Grün - den. Spuren nachwirkenden

${ }^{26}$ E. Eichmann, Acht und Bann im Reichsrecht des Mittelalters, Paderborn 1909, S. 19; Ansätze zur Allgemeinorientierung S. 18-26, vgl. $112 \mathrm{ff}$.

${ }^{27}$ Concil. Vernense (Verneuil bei Senlis) 755 - erstes Reformkonzil Pippins I. als König, von ihm selbst einberufen und publiziert -, c. 9 (MHG Cap. I, S. 35, 17 ff.): Ein Exkommunizierter, der sich verhält wie oben, regis iudicio exilio condamnetur. - Karl d. Gr., Capitula de rebus eccle - siasticis (ca. a. 787/813), c. 3-4 (MGH Cap. I, S. 186) verfügt schrittweise Verschärfung der Strafen gegen Zehntverweigerer, im zweiten Schritt zusätzlich zur Geldstrafe bannum nostrum; [...] de tertio autem, ut sacrilegus habeatur, sit in exilium missus et res eius in fiscum nostrum redigantur. Anders ders., z. B. nach Annal. Mettens. prior. a. 777 (MGH SRG, 1895, S. 86): Auf einem Reichstag in Paderborn innumerabilis turba Saxonum [...] baptizata est et [...] ingenuitatem et possessionem eorum regi Carolo per manus in pignus tradiderunt, ut, si amplius mutassent fidem eorum, in servitium sempiternum perdita hereditate incidissent (sinngleich, mit schwieriger Rechtsterminologie, anderweit). Hier tritt Verknechtung anstelle des Exils, die Güterkonfiskation bleibt. - Vgl. flg. Anm.

${ }^{28}$ Dazu H.-D. Kahl, Karl d. Gr. und die Sachsen. Stufen und Motive einer historischen „Eska - lation“, bei H. Ludat - R. C. Schwinges (Hg.), Politik, Gesellschaft, Geschichts schreibung, Gießener Festgabe für František Graus, Köln-Wien 1982, S. 49-130. Neueste Zusammen - fassung m. Lit.: A. Angenendt, Liudger, Münster 2005, S. 78-85.

${ }^{29}$ R. Bratož, La cristianizzazione degli Slavi negli Atti del convegno „ad ripas Danubii“ et del concilio di Cividale. Con un' appendice di T. Knific, in: XII Centenario del Concilio di Cividale (796-1996), Convegno storico/ teologico, Atti. Udine 1998, S. 145-202.

${ }^{30}$ H.-K. Kahl, Randbemerkungen zur Christianisierung der Sachsen, bei w. Lammers (Hg.), Die Eingliederung der Sachsen in das Frankenreich (Wege d. Forschung 185), Darmstadt 1970, bes. S. 519-526 (aus H.-W. Krumwiede [Hg.]., Vorchristlich-christliche Frühgeschichte in Nieder - sachsen. Beih. z. Jahrb. d. Ges. f. niedersächs. Kirchengesch. 64, 1966). 
alten Glaubens und Kultes finden sich unter den Sachsen noch jahrhundertelang, und das ohne Nachrichten weiterer drastischer Verfolgung. ${ }^{31}$

Neue Probleme schoben sich in den Vordergrund: „Heiden“ drängten von allen Seiten heran - teils als Beutemacher, die wieder verschwanden, teils aber mit dem Ansinnen, Handelsbeziehungen aufzunehmen, ja Wohnsitze zu erhalten, dies vor allem im West fran - ken reich und im angelsächsischen England. Wie es scheint, wurde dadurch das Bewußt - sein in bestimmter Richtung geschärft, nämlich der, daß Christianisierung nicht allein Menschen und Menschengruppen betraf, sondern auch Länder. Waren diese erst einmal mit einem Netz geweihter Stätten überzogen - mit Kirchen und Klöstern, Kapellen und Friedhöfen -, so kam ihnen eine Art „Charakter“ zu, der als unauslöschlich galt, vergleichbar demjenigen, den nach Kirchenlehre das Taufsakrament dem einzelnen Christen einprägt. ${ }^{32}$ Das 9. Jh. ist erfüllt von frustrationsreichen Versuchen, unerwünschte Ein dring - linge wenigstens zur Taufe zu bewegen. Sie kleiden sich vielfach in hochoffizielle Ver - träge, die karolingische und angelsächsische Herrscher mit den Anführern wikingischer bzw. normannischer Kontingente schlossen, gipfelnd in der Übereinkunft von St.-Clairsur- Epte (wohl 911), die den Normannen einen beträchtlichen Teil der später nach ihnen benannten Normandie auslieferte. ${ }^{33}$ Es mag im Anschluß an solche Erfahrungen erfolgt sein, daß kirchliche Aufmerksamkeit sich der Bekämpfung heidnischer Relikte im eigenen Lager wieder stärker zuwandte, für die auch $\mathrm{T}$ ein mindestens frühes Zeugnis liefert.

Im 11. Jh. setzten Entwicklungen ein, die für hartnäckig „falschen“ Glauben auf Todesstrafe drängten, in anderen Fällen von Bußverweigerung auf Acht, also Friedlos le - gung, die dem Betroffenen nicht unbedingt das Verlassen des Landes auferlegte, doch jeden Verkehr mit ihm untersagte und jedermann freistellte, ihn totzuschlagen. ${ }^{34}$ Mit „falschem" Glauben war in erster Linie Ketzerei (Häresie) gemeint; Rückfall zum Heidentum (Apostasie) galt als eine ihrer Sonderformen. Fortführung oder Erneuerung einzelner vorchristlicher Bräuche gehörte, strenggenommen, mit in diesen Rahmen, doch in dem synkretistischen Kontext, der vor dem neuen missionarischen Ausgreifen des 12. Jh. mehr oder weniger überall zu unterstellen ist und jedenfalls für die mutmaßliche Umwelt von $\mathrm{T}^{35}$ - in diesem Kontext dürfte solche Abweichung kaum als Abfall vom Glauben überhaupt gewertet worden sein. Datierung des Übergangs zu diesen neuen Auffassungen ist schwierig, schon weil mit starken landschaftlichen Differenzen zu rechnen ist. Ganz sicher aber ist die Erinnerung an die Lösung der frühkarolingischen Zeit nicht vollständig

\footnotetext{
${ }^{31}$ Ebd., S. 508-519.

${ }^{32}$ H.-D. Kahl, Compellere intrare. Die Wendenpolitik Bruns von Querfurt usw. bei H. Beumann (Hg.), Heidenmission und Kreuzzugsgedanke in der deutschen Ostpolitik des Mittelalters (Wege d. Forschung 7), Darmstadt 1963-1973, S. 204 u. u. bes. 210 ff. (aus Zschr. f. Ostforsch. 2, 1953); vgl. Dens., Bausteine zur Grundlegung einer missionsgeschichtl. Phänomenologie des Hochmittelalters, in: Miscellanea Historiae Ecclesiasticae (1), Congrès de Stockholm 1960, Louvain 1961, S. 62-69 (die dort zitierten „Beiträge zur Brandenburgischen Geschichte“ erschienen 1964 unter dem Titel: Slawen und Deutsche in der brandenburgischen Gesch. d. 12. Jh.s).

${ }^{33}$ Zusammenfassend behandelt bei A. Angenendt, Kaiserherrschaft und Königstaufe, Berlin-N.Y. 1984, bes. S. 259-273; zum genannten Vertrag S. 263-265; vgl. H. Hattenhauer, Die Aufnahme der Normannen in das Westfränk. Reich, Göttingen 1990, passim; A. Renoux, LMA VII (1995), Sp. 1140. Für England bes. A. P. Smyth, Scandinavian Kings in the British Isles 850-880, Oxford 977.

${ }^{34}$ Eichmann, passim

${ }^{35}$ Vgl. Kahl 2004, S. 33 ff. u. 38 f.
} 
erloschen. Im 12. Jh. suchte Hildegard von Bingen (1098-1179) solchem Trend entgegenzusteuern: Auch Häretiker seien Gottes Ebenbild; das Land werde zwar durch ihre teuflischen Umtriebe befleckt, doch umbringen solle man sie deswegen nicht, sondern lediglich enteignen und sie dann hinaustreiben. ${ }^{36}$ Papst Innozenz III. dachte 1208, als die Albigenserfrage verstärkte Dringlichkeit gewann, sogar an planmäßige Entvölkerung und Neubesiedelung ganzer Landschaften. ${ }^{37}$

Außerordentlich bemerkenswert ist ein Vertrag, der 1249 auf der Deutschordensburg Christburg im nachmaligen Westpreußen (nahe dem späteren Marienburg/Malbork) zu - stan dekam. Parteien waren der Deutschritterorden und die Prußen, die er zu bekehren strebte, die sich aber gegen gleichzeitige Aufrichtung seiner Herrschaft wehrten; die Abmachung sollte nach schweren Kämpfen eine Abfallsbewegung friedlich beenden. Es handelte sich also einerseits um eine kirchliche Instanz, andererseits um ein Gemenge von Getauften, die zu ihrer angestammten Religion zurückgekehrt, die also Apostaten waren, und noch ungetauften „Heiden“. Ausschlaggebend für die Gestaltung wurde ein päpstlicher Legat, Kardinal Jakob von Albano (auch: von Lüttich), der als Vermittler wirkte - 12 Jahre später übernächster Papst (Urban IV., 1261-1264); hinter ihm aber stand der Papst der Zeit, Innozenz IV. (1243-1254), ein bedeutender Kanonist, der in seinen Schriften darauf bestand, den „Ungläubigen“ mehr eigene Rechte zuzugestehen, als andere es zulassen wollten. Die Preußen erhielten Garantie ihrer angestammten Freiheitsrechte, so daß der Orden sich auf eine bloße Schutzfunktion für ihr Christentum beschränkt sah; sie gelobten dafür, endgültig von allem Heidentum - Kult wie Glauben - abzulassen, und unterwarfen sich der katholischen Kirche (was natürlich deren Normen einschloß, ob sie ihnen bekannt waren oder nicht). Die Güter (bona) derer, die weiterhin die Taufe verweigerten, sollten eingezogen werden (publicentur), ebenso diejenigen derer, die ihrer Kindertauf - pflicht nicht genügten; die Betreffenden sollten aus dem Gebiet der Christen (extra christianorum fines) ausgetrieben werden (expellantur), „damit nicht die guten Sitten anderer durch ihre verderblichen Gespräche korrumpiert werden", und zwar nackt im Hemd (nudi in tunica). ${ }^{38}$ Von Strafen für bisherigen Abfall ist keine Rede - er erhielt also stillschweigend Amnestie, um nicht zu großen Widerstand gegen die Rückkehr wachzurufen. Der Teufel etwaiger neuer Apostasien wurde nicht erst an die Wand gemalt - dafür genügte offenbar das festliegende Strafrecht der Kirche, der die Prußen sich unterwarfen. Es ist kaum zu bezweifeln, daß dieses Vertragswerk in hohem Grade auf den Instruktionen des Papstes beruht, und es sollte ebensowenig unabhängig von dessen kanonistischen Thesen behandelt werden wie umgekehrt diese von ihm, so sehr dies auch üblich geworden ist.

Der Unterschied zu T liegt auf der Hand. In einem Vertrag werden die Partner gefragt und können ihre Zustimmung geben, selbst wenn sie dies widerwillig tun; T dagegen ist eine Art Gesetz, das über die Köpfe der Betroffenen hinweg über sie verfügt. Das hängt mit der ungleichen Ausgangslage zusammen: Neuchristen, denen der Übertritt möglichst weitgehend erleichtert werden soll, dort - ein dem Anspruch nach längst christianisier-

\footnotetext{
${ }^{36}$ Hildeg. Bingens., ep. 47 ad praelatos Moguntinenses (Migne, Patr. Lat. 197, 232 D): . populum istum ab ecclesia, facultatibus suis privatum, expellando et non occidendo effugate, quoniam forma dei sunt ...

${ }^{37}$ H. Roscher, Papst Innozenz III. und die Kreuzzüge, Göttingen 1969, S. 225 f. u. 227.

${ }^{38}$ Preußisches Urkundenbuch. Polit. Abt. I,1 (1909), Nr. 218,64 ff. 106 ff. (2. 161 f.). Dazu C. A. Lückerath, Christburger Vertrag, in: LMA II (1983), Sp. 1907 f. (Lit.); zu Innozenz IV.: G. Schwarz, in: Theolog. Realenzyklopädie XVI (1987), S. 182-185; ergänzend: B. Robert, LMA V (1991), Sp. 437 f.
} 
tes Land mit fest etablierter Kirche im Rahmen gesicherter Herrschaft eines christlichen Staatswesens hier. Gleichwohl ist die innere Nähe beider Verlautbarungen unverkennbar: beiderseits Normen katholischen Lebens als Maßstab mit besonderer, wenn auch nicht ausschließlicher Spitze gegen Nachwirkungen vorchristlicher Religion, beiderseits gleiche Zwangsmittel weltlichen Strafvollzugs gegen Abweichler. Ein Traditionsstrang wird faßbar, dünn nur belegt, der jedoch in wie immer gearteter Kontinuität gewirkt haben muß. In diesem Strang aber nimmt $\mathrm{T}$ eine hervorragende Stellung ein, die Beachtung verdient.

Hat Rom nur an dieser einen Stelle in vergleichbarer Richtung gewirkt? In Norwegen haben sich einzellandschaftliche „Christenrechte“ erhalten. Sie beharren darauf, daß jeder - mann im Lande verpflichtet sei, Christ zu sein, und regeln die strafrechtliche Behand lung etwaiger Verstöße gegen kirchliche Normen. Es sind, wohlgemerkt, nicht Verfügungen geistlicher Instanzen - es handelt sich um Thingbeschlüsse, also „staatliches“ Recht. Geistliche Strafmittel kommen daher nicht vor. Vielfach begnügen die Texte sich mit Vermögensstrafen, für schwere Fälle aber drohen sie Friedlosigkeit an, sowohl für den Täter wie für seine Habe, deren Aufteilung zwischen König, Bischof und etwaigen anderen dann sorgfältig geregelt wird. Das gilt für Fortführung von Relikten der vorchristlichen Religion, nicht zuletzt Beisetzung von Toten in Hügeln (haugar!) oder sonst außerhalb des Friedhofs, ferner für Verweigerung der Kindertaufpflicht, für Fastenbrechen, widernatürliche Unzucht, bestimmte eherechtliche Verstöße und anderes mehr. Aus führlich wird der Fall behandelt, „wenn ein Heidenmann in unser Land kommt“: Er hat bei nächster Gelegenheit die Taufe zu nehmen; bis dahin darf man ihn verpflegen, aber nicht mit ihm zusammen essen - weigert er sich, so hat er binnen fünf Tagen das Land zu verlassen, und wer ihn dann länger als eine Nacht beherbergt, gar mit ihm gemeinsam speist, verfällt einer Geldbuße, die dem Wert einer Herde von 148 vollwertigen Rindern entspricht. ${ }^{39}$ Der Heide als solcher ist unrein und eine Gefahr für das Land. Wer kann schon wissen, was an Teuflischem von ihm ausstrahlt!

All diese Texte zeigen deutlich verschiedene Entstehungsgeschichten - teilweise stehen diese merkwürdig unverbunden und unausgeglichen nebeneinander. Mehrere davon gehen unstreitig ins 11. Jh. zurück, das Norwegen seine Christianisierung in ziemlich gewalt haften Formen brachte. Zum ältesten Band können die genannten Festsetzungen kaum gehören: Sie setzen voraus, daß der Sieg des neuen Glaubens im Lande nicht mehr nur Anspruch war, sondern Realität; daß also von den Ausweisungsdrohungen nur eine Minder heit noch betroffen werden konnte. Dazu fällt auf, daß keine der verfügbaren Handschriften dieser Christenrechte vor die Wirksamkeit eines weiteren Kardinals zu rück reicht, nämlich des Nikolaus Breakspeare, nachmals Papst Hadrian IV. (1154-1159), der 1152/53 längere Zeit als Legat Papst Eugens III. in Skandinavien weilte. Er hat damals der norwegischen Kirche als nunmehr selbständiger Kirchenprovinz unmittelbar unter Rom eine dem kanonischen Recht gemäße Form gegeben, an der es bisher gefehlt hatte, und zahlreiche weitere Reformen durchgesetzt bis hin zum Verbot des Waffentragens an Handelsplätzen, und seine Persönlichkeit hinterließ einen stark nachwirkenden freund-

\footnotetext{
${ }^{39}$ R. Meissner, Die norwegische Volkskirche nach den vier alten Christenrechten, Germanen rechte, N. F.: Deutschrechtl. Archiv, 2. Heft (Weimar 1941), passim; nicht behandelt der „Heiden mann“ in „unserem Land“ - dazu H.-D. Kahl, Das altschonische Recht als Quelle zur Missionsgesch. usw., in: Die Welt als Geschichte 1/1957, S. 27 f., vgl. 46 f. Zum Allgemeinen: A. Bø u. a., Kristenrettar, Norge, in: Kulturhistorsk Leksikon för nordisk middelalder IX (1964), Sp. 297-304 m. Lit.; zu den Hügelgräbern Ders u. S. Lindqvist, Hauglegging, ebd. VI (1961), Sp. 246-250.
} 
lichen Eindruck. ${ }^{40}$ Daß das Königtum bald mit weiteren Reformen des weltlichen Rechts nachzog, verhinderten Rivalitätskämpfe mehrerer Prätendenten, die über ein Jahrzehnt in Anspruch nahmen. Erst nach 1163 geschah mehr in dieser Richtung. Daß davon dann auch die "Christenrechte“ betroffen wurden, ist bezeugt, ohne daß der damalige Anteil sich einwandfrei abgrenzen läßt; auch diese Reformen liegen noch vor deren ersten Handschriften.

Gibt es einen Anteil des Kardinals Nikolaus an dem, was uns schließlich greifbar wird? Dürfte das so rekonstruiert werden, so kämen wir nochmals in die Zeit Hildegards von Bingen und auf Papst Eugen im Hintergrund. Doch die Quellen schweigen eisern. Sie geben nicht einmal den Blick auf Wahrscheinlichkeiten frei. Die harten Bestimmungen der norwegischen Christenrechte können durchaus schon einer der jüngeren Schichten des 11. Jh. angehören; möglicherweise wäre dann mit Einflüssen aus der deutschen und der englischen Kirche zu rechnen, die beide lange zur Entwicklung der norwegischen beigetragen haben.

Nur am Rande kann hier auf das berüchtigte Problem der sog. eiectio Slavorum hingewiesen werden, das für die deutschen Kolonisationsgebiete östlich der Elbe im 12. und 13. Jh. von sich reden macht. Es ist vielschichtig und muß differenziert betrachtet werden; teilweise gehört es zweifellos in den hier verfolgten Fragenkreis hinein, teilweise ist es ebenso zweifellos anders gelagert. Seine verworrenen Fäden auseinanderzuziehen, ist hier nicht der Ort. ${ }^{41}$ Überhaupt erübrigt es sich, die Umschau an dieser Stelle fortzusetzen. Auch so schon hat sie deutlich gemacht: T steht, was seine Beugungsstrafen angeht, in einer langen Überlieferungskette, die sich nicht auf Deutschland beschränkt. Unter ihren Gliedern kommt diesem Synodalschluß eine beachtliche Stellung zu. Allerdings hilft dies nur zur motivgeschichtlichen Einordnung. Für die chronologische hat sich dabei im Grunde lediglich ergeben, daß die Warnung vor gar zu frühem Ansatz der Entstehungszeit Verstärkung erfuhr. Im übrigen ist das Vergleichsmaterial zu diesem strafrechtlichen Aspekt zu weit gestreut, um noch neue Anhaltspunkte für die Datierung zu liefern.

\section{V.}

Suchen wir eine vorläufige Summe zu ziehen, so läßt sich festhalten: T entstand im Verbreitungsgebiet des ahd. Wortes houc, also nicht südlicher als im Maingebiet. In engere Wahl kommt, wie es scheint, die Diözese Würzburg. Inhaltliche Analysen führen, soweit sie Datierungshinweise erbringen, immer wieder in spätkarolingisch-frühnachkarolingische Zeit; der Gebrauch des dux engt den Blick, wenn man in Mainfranken bleibt, auf die Spanne ein, in der der eine oder andere Konradiner dort informell mit diesem Ausdruck belegt werden konnte, bevor daraus eine feste Rangbezeichnung wurde. Das führt auf erstaunlich präzise Daten, etwa 906-939, doch kommt wegen des vorausgesetzten engen Zusammenspiels geistlicher und weltlicher Instanzen schon die Zeit König Heinrichs I. (ab 919) kaum noch in die engere Wahl.

\footnotetext{
${ }^{40}$ Hier genüge der Hinweis auf O. Kolsrud, Norges Kyrkjesoga I, Oslo 1958, S. 186-202; F.-J. Schma le, Hadrian 4., in: LMA IV (1989), Sp. 1823 mit weiteren Hinweisen. Zum Nachleben in der Erinne rung des Nordens: Snorri Sturluson, Heimskringla, Uphaf Inga konungs, c. 23 (Udg. af F. Jónsson, København 1911, p. 587). Vgl. auch M. Gerhard - W. Hubatsch, Norweg. Gesch., 2. Aufl. Bonn 1963, S. 93-95.

${ }^{41}$ Hinweise: H.-D. Kahl, Kulturbilder im vorchristlichen Slawentum, in: Studia Mythologica Slavica 8 (2005), S. 22 f. m. Anm. 37.
} 
Bei derart präziser Eingrenzung allein aus Rückschlüssen fühlt man sich nicht wohl. Es trifft sich jedoch, daß zwischen 793 und 1008 ausgerechnet die so herauspräparierte Phase die einzige ist, für die Würzburg mit nachweisbaren Herrscheraufenthalten aufwarten kann. Konrad I. hat dort sogar mehrmals geurkundet, 915 und $918 .{ }^{42}$ Thiodo, damals Bischof des Ortes (908-931), scheint, soweit das karge Quellenmaterial Einblick gestattet, diesem Herrscher näher verbunden gewesen zu sein..$^{43}$ Offenbar kam er aus dem engeren Umkreis der Konradiner und war nicht ohne deren Einfluß in sein Amt gelangt. In der Umgebung Konrads erscheint er schon im Jahr vor dessen Königserhebung, und bei diesem Akt war er mindestens anwesend; er erhielt damals das ersterhaltene Privileg dieses Herrschers, das ihn auffällig betont herausstreicht; es betrifft u. a. die Übertragung von slawischen Siedlungen (Sclavinis oppidis) aus Reichsgut zugunsten des Hochstiftes und seines Eigenklosters Ansbach. ${ }^{44} 915$ urkundete der Herrscher in Würzburg selbst zugunsten eines bischöflichen Vasallen; die Intervenientenliste läßt erkennen, daß auch mehrere Mitglieder des Episkopats anwesend waren, darunter Erzbischof Heriger von Mainz (913-927).$^{45}$ Das nächste Jahr sah die Synode von Hohenaltheim. Daß Thiodo dabei war, läßt sich nur vermuten - mit der Unterschriftenliste zu den Akten fehlt jede Kontroll möglichkeit. ${ }^{46}$ Es wäre merkwürdig, wenn gerade er gefehlt hätte.

In seinem letzten Lebensjahr weilte der König nochmals im heutigen engeren Franken, offenbar für längere Zeit. Auch dabei berührte er Würzburg. Anfang Juli ließ er dort an zwei aufeinanderfolgenden Tagen Urkunden zugunsten des Bischofs ausfertigen: Bestätigung der alten Immunitätsprivilegien (unter Erwähnung von accolas vel Sclavos, was zu dem von T vorgeführten Bild der Bevölkerung paßt), ${ }^{47}$ und von Zollvergünsti - gungen. ${ }^{48}$ Das deutet an, daß Konrad damals dort nicht lediglich verweilte, sondern auch mit speziellen Problemen des gastgebenden Bistums befaßt war - es sind die einzigen Beurkundungen, die wir aus diesem Aufenthalt kennen. Nicht mehr erneuert wurde das alte Sonderprivileg der Karlszeit über die Slawenkirchen: Ihre Rechtsstellung im Bischofsgut war wohl seit dem letzten Mal (889) dermaßen selbstverständlich geworden, daß eine wiederholte Einschärfung sich erübrigen konnte - die allgemeine Bestätigung des $\mathrm{Be}$ sitzstandes erfaßte sie hinreichend mit. Sich statt dessen nun mit der kirchlichen Disziplin zugehöriger Gemeinden zu befassen, lag kaum fern, und ebensowenig, sie beim fortgeschrittenen Entwicklungsstand nicht mehr als Sonderproblem für sich zu behandeln,

\footnotetext{
${ }^{42}$ Würzburger Herrscheraufenthalte verzeichnet A. Wendehorst, Das Bistum Würzburg (Germ. Sacra, N. F. 1), Berlin 1962 ff., im Zuge der Behandlung der Reichstätigkeit der einzelnen Bischöfe. Für die Zeit bis 908 weist K. Lindner, Untersuchungen zur Frühgesch. d. Bistums Würzburg u. d. Würzburger Raumes, Göttingen 1972, S. 208-212, passim, sowie 237 auf weitere mögliche Termine hin, die jedoch unbezeugt bleiben. Ein Aufenthalt Ottos I. 961 in Würz - burg ist nur spät und in fragwürdiger Quelle behauptet; das Itinerar des Königs ließe dafür Raum (Wendehorst I, S. 64); für einen Besuch jedenfalls der Kaiserin 995 ist nur die Ankündigung bekannt, nicht die Ausführung (ebd., S. 72). Königsurkunden für Würzburg zwischen 793 und 1008 zeigen Ausstellungsorte wie Frankfurt/M., Magdeburg, Forchheim, Pöhlde; Falsifikate, denen echte Diplome zum Opfer gefallen scheinen, erschweren den Einblick.

${ }^{43}$ Dazu Wendehorst I, S. 55-58; vgl. auch E. Dümmler, Gesch. d. ostfränk. Reiches III, 2. Aufl. Leipzig $1888=$ Darmstadt 1960, S. 576, 598, 614.

${ }^{44}$ DKr I,1, 911 XI 10 (MGH DD I, S. 2): ...rogatu Diotonis venerabilis et dilecti episcopi nostri [...] praefatus vir venerabilis Dioto praesul egregius...

${ }^{45}$ DKr I, 27915 XI 6 (2. 25 f.).

${ }^{46}$ Wolter (wie Anm. 6), S. 12, vgl. $17 \mathrm{f}$.

${ }^{47}$ DKr I,34 918 VII 4 (S. 31), nach DArn 66 (MGH DKar III, S. 98).

${ }^{48}$ DKr I 35918 VII 5 (S. 31).
} 
sondern im Rahmen der Gesamtsituation im Diözesangebiet, das auch weitere nationes einschloß.

Allerdings fielen die damit berührten Probleme nicht in königliche, sondern in geistliche Zuständigkeit. Wenige Tage nach Ausstellung jener Urkunden, am 8. Juli, war Kilians tag, Fest des Hauptpatrons von Würzburg. Der König wird kaum schon vorher abgereist sein. Ein mehrtägiger Herrscheraufenthalt, ohnedies nicht von einem Tag zum anderen zu organisieren, konnte Anlaß geben, den Diözesanklerus zahlreich zusammenzurufen, schon um dem hohen Besuch einen möglichst festlichen Empfang zu bereiten: Der adventus regis war ja im Zeremoniell seit alters herausgehoben. ${ }^{49}$ Die Zeit pflegte kirchliche Synoden nicht klar von anderen repräsentativen Versammlungen zu trennen. ${ }^{50}$ Wurde T auf einer solchen im Beisein des Herrschers beschlossen, so wäre eine Schwierigkeit behoben, auf die die Forschung schon wiederholt hinzuweisen hatte: Die Art, wie dort weltliche Amtsträger in das Vollstreckungsverfahren eingebunden werden, sprengt den Umkreis, in dem die Kirche eigenmächtig Regelungen zu treffen vermochte - sie setzt eigentlich eine Bestätigung durch den Herrscher voraus. ${ }^{51}$ Wurden die Be schlüsse in seinem Beisein gefaßt und verkündet, so erübrigte sich jeder zusätzliche Schritt, um ihnen uneingeschränkte Rechtskraft zu verleihen.

Ist das Bündel von Indizien, die sich damit zusammenfügen, gar zu stimmig, gar zu verführerisch, um sich darauf einzulassen? Unbedingt sind wir nicht auf diese Mög lich - keiten angewiesen. Noch drei Monate später erscheint Konrad auf fränkischem Boden, dann in der Königspfalz Forchheim. Er urkundet dort, im nächsterhaltenen Diplom nach den beiden Würzburger Stücken, für das Bistum Eichstätt; die Intervenientenliste zeigt, daß damals auch Erzbischof Heriger wieder zugegen war, außerdem Thiodo, gleichsam der Nachbar, und ein comes Eberhard. ${ }^{52}$ Es ist kaum auszuschließen, daß sich hinter diesem letzten niemand anders verbirgt, als der vorhin angesprochene Königsbruder, der sonst auch als $d u x$ bezeichnet wird, obwohl diese Identifikation nicht ganz sicher scheint.$^{53}$ Die Teilnahme des Metropoliten, der sich selten in diesen Gegenden sehen ließ, spricht für einen bedeutenden Anlaß, den wir leider nicht kennen. Wenn T dort beschlossen wurde, wären Interessen, die Würzburg und Eichstätt gemeinsam berührten, vor einem breiteren Forum erörtert worden. Vielleicht jedoch war es zu breit. Vorher, im Juli, war der König sicherlich stärker auf Würzburger Probleme fixiert, und jenes hougir mag zusätzlich für seinen damaligen Aufenthaltsort sprechen, doch sollten wir hier nichts pressen. Jedenfalls zögere ich nicht, die Entstehung von T am ehesten in diese Sommermonate 918 zu setzen,

${ }^{49}$ Th. Kölzer, adventus regis, in LMA I (1980), Sp. $170 \mathrm{f}$.

${ }^{50} \mathrm{Vgl}$. Z. B. I. Schröder, Die westfränk. Synoden von 888 bis 987, München 1980, S. 7-11.

${ }_{51}$ Kahl, 2004, S. 30, Anm. 67-68. Von dort zitierten Stimmen hier hervorzuheben: Rich. Schröder, Die Ausbreitung der salischen Franken, in: Forsch. z. deutschen Gesch. 19 (1879), S. 140, der „mit einem Würzburger Synodalschluß, wenn auch vielleicht in Form eines königlichen Gesetzes" rechnet.

${ }^{52}$ DKr I, 36, 918 IX 9 (S. 33).

${ }^{53}$ Das Register des Bandes, S. 686, schlägt ohne Begründung einen gleichnamigen Grafen aus dem österreichischen Donaugebiet vor. Die dort auf den Konradiner bezogenen Nennungen zeigen, daß er öfters ohne besondere Hervorhebung unter anderen comites genannt wird, einmal - DKr I, 23 (S. 22, 23) 914 VI 7, also schon verhältnismäßig früh - als marchio; als Königs bruder nur hervorgehoben, wenn er allein herausgestellt wird. Den $d u x$ hat König Konrad, soviel bekannt, niemals verwendet. Ihn in T einzusetzen, war wohl die einzige Möglichkeit, über den comes hinaus eine höhere Instanz zu fixieren, wie sie der dortige Verfahrensgang brauchte. Angesichts der Bedeutung Eberhards für die dortige Landesgeschichte (vgl. E. Karpf, LMA III, 1986, Sp. 1512) wird man bei einer Gelegenheit, die selbst den Erzbischof von Mainz anzog, in erster Linie ihn erwarten. 
in das dritte Quartal dieses Jahres, nicht auf weit entferntem Schauplatz, sondern unmittelbar auf ostfränkischem Boden.

Von hier aus scheint sich zugleich eine besondere Merkwürdigkeit aufzuklären, die sich, so gut wie unbeachtet, mit T verknüpft. Verfolgt werden sollen Feiertagsschändung, Fastenbrechen, "götzendienerische“ Praktiken, Zehntverweigerung und Boykott des Sends; dazu werden Verfahrensfragen geregelt. All das könnte in einem ganz gewöhnlichen Sendrecht stehen, auch wenn die Drastik auffällt, in einem Sendrecht für Laien. Aber das ist T nicht ohne weiteres. Es sieht Ausnahmen vor. Sie stehen im Rubrum, das die Geltung der Bestimmungen einschränkt auf Sclavi vel ceterae nationes, qui nec pacto nec lege Salica utuntur. Zeiten, die mit mehr oder weniger nationalistisch verblendeten Augen sahen, nahmen auf, daß damit das Slawentum angesprochen war, und prägten daher für $\mathrm{T}$ Bezeichnungen wie „Sendrecht der Main- und Rednitzwenden “ ${ }^{54}$ oder, noch stärker vereinfacht, „Slawensendrecht“ ${ }^{55}$ Doch das trifft bestenfalls eine Halbwahrheit. Die benannte Gruppierung ist in T ausdrücklich mit weiteren auf eine Stufe gestellt, die nach Lage der Dinge schwerlich etwas anderes sein können als Angehörige germanischer Stammesreste aus der Völkerwanderungszeit, später gemeinsam mit den „Wenden“ im deutschen Oberfrankentum aufgegangen. Die so geschaffene Gesamtheit aber wird zwei benannten Rechtsgruppen gegenübergestellt, hinter denen man wohl Franken ribuarischen und salischen Rechts zu suchen hat. Für sie gelten die aufgeführten Bestimmungen nicht. ${ }^{56}$ Welch merkwürdige Zweiteilung der Laienwelt! Sie ist im Sendgerichtswesen gänzlich ungewöhnlich, vielleicht sogar einmalig, und sie bedarf daher besonderer Erklärung.

Zwei Gründe, soviel ich sehe, kommen zusammen: einer aus dem gegebenen $\mathrm{Zu}$ stand von Reich und Königtum, der zweite aus nachwirkender karolingischer Reichsideologie.

Die Regierung Konrads I. stand wie keine vor ihm im Zeichen von Vorwehen des aufkommenden sog. jüngeren Stammesherzogtums. ${ }^{57}$ Der Erfolg von Hohenaltheim war nur partiell gewesen und nicht von Dauer. Die wenigen Folgejahre brachten ständig neue Rück - schläge, in Sachsen, in Bayern und auch in Schwaben. Einzig Ostfranken, wo die herzogsähnliche Stellung beim konradinischen Hause selbst lag, bot eine einigermaßen verläßliche Basis. Die Ungarn blieben ständige Bedrohung, die böhmischen Slawen hatten begonnen, sich deutlicher als früher zu formieren, und sie paktierten dabei wohl zeitweise mit dem ungebärdigen Reitervolk. Das Würzburger Bistumsgebiet lag zwischen all diesen Fronten, gemeinsam mit dem von Eichstätt, doch nicht so stark wie dieses von Bayern her bedrängt. Dieses Gebiet fest in der Hand zu behalten, war für Konrad von höchster Bedeutung: Nicht zufällig wird er sich so viele Sommermonate hindurch in diesem Bereich bewegt haben - sonst läßt das karge Quellenmaterial vergleichbar ausgedehnte Aufenthalte in einer Region nur für Winterszeiten erahnen. Die komplizierte Bevölke rungs struktur, die oben gestreift worden ist, wird die Aufgabe, das Land zu behaupten, nicht leichter gemacht haben: Franken als verhältnismäßig sichere Stütze dürften in weiten Partien wenig mehr gestellt haben als eine dünne Oberschicht, die allerdings vermutlich

\footnotetext{
${ }^{54}$ Dove, wie Anm. 17.

${ }^{55}$ S. Riezler, Bistum Eichstätt und sein Slavensendrecht, in: Forsch. z. dtsch. Gesch. 16 (1876), S. 397-408; Richter-Dove-Kahl (wie Anm. 6); Koeniger 1937 (wie Anm. 7); weiteres bei Kahl 2004, S. 16, Anm. 29.

${ }^{56} \mathrm{Kahl} 2004$, S. 24-30, hier im folgenden ergänzt.

${ }^{57}$ Zum flg. genüge hier der Hinweis auf Dümmler (wie Anm. 43), S. 574-620 u. 635-640.
} 
im ureigensten Interesse zum König hielt; ${ }^{58}$ andere Bevölkerungsgruppen mochten für unerwünschte Einflußnahmen von außen her offen sein. Ihre Loyalität zu sichern, wird man sich als ein wesentliches Anliegen des Herrschers vorstellen dürfen. Mindestens die Slawen wohnten in Randgebieten!

Die Franken haben sich, soweit die Quellen Einblick gestatten, im Lauf des 8. Jh. daran gewöhnt, sich selbst mit dem Gottesvolk des Alten Testaments zu identifizieren, in einer Intensität, die wohl erst von den englischen Puritanern des 17. Jh. wieder erreicht, dann allerdings wohl auch überboten wurde. Gern sonnte man sich in dem Gefühl, einer gens anzugehören, die von Gott selbst gestiftet war, von Christus geliebt, von unanfechtbarer katholischer Rechtgläubigkeit, während die „Barbarenwelt“ noch in Ketzerei verharre; ${ }^{59}$ seit Karl d. Gr. entwickelte sich die merkwürdige, im Grunde unübersetzbare Formel, man habe fidelis Dei et regis zu sein, an Gott zu glauben und ein Getreuer des Königs zu sein, den die feierliche kirchliche Salbung beim Herrschaftsantritt irgendwie in die Nähe des Höchsten gerückt hatte. ${ }^{60}$ Franke sein und ein Christ sein, der den dem Herrscher geleis teten Treueeid nicht durch Abfall nachträglich zum Meineid werden ließ, waren der Idee nach eins.

Wie sehr die Realität diesen berauschenden Wein immer wieder verwässert hat, ist nur zu gut bekannt. Gleichwohl: Bei Lichte besehen, ist die Zahl der Fälle, die Aufsehen genug erregten, um in die Quellen zu dringen, doch relativ gering. Aus Mainfranken ist für die Zeit Konrads I. kein einziger auszumachen. Was es etwa noch an Anhängern der gestürzten Babenberger gab, wird Gründe besessen haben, sich ruhig zu halten. Die eigenen Interessen waren wohl auf seiten des Königs, der mehr geben, aber auch mehr nehmen konnte als jeder andere, am besten gewahrt. Selbstverständlich werden auch unter diesen Franken Verstöße gegen kirchliche Vorschriften vorgekommen sein. Sie zu ahnden und abzustellen, haben aber offenbar normale sendrechtliche Maßnahmen genügt. Wie das geschah, entzieht sich unserem Einblick.

$\mathrm{T}$ hat es nicht mit ihnen, sondern mit anderen zu tun, und mit Hartnäckigkeit, gegen die Abmahnung und leichte Buße nichts half. Sie muß demonstrativ gewirkt haben und damit als Auflehnung sowohl gegen Gott als auch gegen den König. Die politische Situation der letzten Jahre Konrads I., so wird man zu folgern haben, forderte, in gerade diesem Würzburger Diözesangebiet, diesem vorgeschobenen Teil Ostfrankens, mit allen

\footnotetext{
${ }^{58}$ Volle Sicherheit über die konkrete Verteilung von Franken im Lande ist nicht zu gewinnen. Zum all - gemeinen: R. u. U. Koch, Die fränkische Expansion ins Main- und Neckargebiet, in: Die Fran ken, Wegbereiter Europas. Ausstellungskatalog Mainz 1996, S. 270-284, dazu II, S. 902 f. u. 905-914, passim. H.-J. Nitz, Siedlungsgeographische Beiträge zum Problem der fränkischen Staatskolo nisa - tion im süddeutschen Raum, in: Zschr. f. Agrargesch. u. Agrarsoziologie 11 (1963), S. 34-62, erzielt bemerkenswerte Ergebnisse über die Ausbreitung dieser Kolonisation, doch bleibt unvermeidlich offen, welche Ethnica im Einzelfall herangezogen wurden. Nicht erfaßbar bleibt Grund - herrschaft fränkischer Oberschicht über vorgefundenen älteren Strukturen. Nicht feststellbar ist, wie in den übrigen Fällen auch, der zahlenmäßige Anteil an der Gesamtbevölkerung. Auch nur eine relative Mehrheit ist schwerlich anzunehmen. Vgl. auch H. Nitz, Siedlungsstrukturen der königlichen und adeligen Grundherrschaft, bei W. Rösener (Hg.), Strukturen der Grundherrschaft im frühen Mittelalter (Veröff. d. Max-Planck- Inst. f. Gesch. 92), Göttingen 1989, bes. S. 421-423.

${ }^{59}$ Bezeichnend der Prolog der Lex Salica mit seinen verschiedenen Entwicklungsstadien, bes. Fassung D (um 760; MGH LNG IV/2, 1969, S. 3-8, passim). Weiteres bei Kahl 2004, S. 28 f. m. Anm. 64-65, dazu noch A. Hauck, Kirchengesch. I, S. 172 ff., 198 ff.

${ }^{60}$ Kahl 2004, S. 28-30, insbes. nach H. Helbig, Fideles Dei et regis, in: Arch. f. Kulturgesch. 33 (1951), bes. S. 283-291; zu ergänzen durch W. Schlesinger, Beitr. z. deutschen Verf.Gesch. I, Göttingen 1963, S. 108-215, 231 f., 325 ff., 332 f. - Zur Herrschersalbung: H. H. Anton, Salbung II, in: LMA VII (1995), Sp. 1289-1292 (reiche Lit.).
} 
nur erdenklichen Mitteln gegen solche Auflehnung vorzugehen. Die Kirche war geeignet, mit ihren Mitteln als Instrument der Herrschaftssicherung zu dienen, wie sie es in Hohen alt - heim gewesen war, nur jetzt auf anderer Ebene: nicht gegenüber den aufstrebenden Mag - naten im Reich, sondern im Hinblick auf breite Bevölkerungsschichten. In den vorliegenden Beschlüssen haben wir damit nicht einfach ein „Würzburger Sendrecht“ vor uns, wie man gelegentlich sagen wollte, ${ }^{61}$ sondern ein „Würzburger Sondersendrecht für Nicht - franken", die fester in die Kirche und damit in das Reich eingebunden werden sollten.

Die Härte, die dabei eingesetzt wird, fällt auf, jedenfalls uns. Sie wird möglich durch die intensive Einschaltung weltlicher Amtsträger bis hinauf zur Ebene unmittelbar unter dem König selbst. Mit dieser Härte steht der Würzburger Text zwischen zwei Extremen, der berüchtigten Capitulatio de partibus Saxoniae Karls d. Gr., zur mutmaßlichen Ent stehungszeit gut 130 Jahre alt, und einer kleinen canones-Sammlung, die Erzbischof Hervé (Heriveus) von Reims um 914/922 zusammenstellte, also ziemlich genau zeitgenössisch; ${ }^{62}$ die Capitulatio galt einem Eroberungsgebiet, in dem der Frankenkönig eine nicht mehr ernstlich zu erschütternde Stellung gewonnen hatte; ihre ständige Todes drohung war ein ungewolltes Eingeständnis, daß die von ihm angewandten Methoden gleichwohl versagt hatten. Hervé arbeitete im Interesse der Normannenmission, die jener Vertrag von St.Clairsur- Epte in ein neues Stadium befördert hatte, dabei aber für eine Kirche, die nicht gerade ein machtvolles Königtum hinter sich hatte; sie mußte froh sein, wenn die Eindringlinge sie einigermaßen gewähren ließen, und konnte nichts tun, als den im Grunde Widerstrebenden goldene Brücken zu bauen. Für Drohungen, gleich welcher Art, war da kein Raum.

Hinter dem Würzburger Sondersendrecht steht ein gemeinsames Interesse von Kirche und Königtum in einem sozusagen altchristianisierten Land, in dem religionspolitisch nur noch gegen eine Minderheit vorzugehen war. Dafür genügten Vermögenseinziehung und Verbannung. Doch ein hartes Brot für die Betroffenen waren auch sie. Allerdings ahnen wir nicht, wie viele damit abgespeist wurden. Wir haben nur den Rechtstext - nichts zeugt für Häufigkeit und Art seiner Anwendung. Gab es Schwierigkeiten auf seiten derer, die die Durchführung übernehmen sollten? Der Text deutet an, daß der eine oder andere sich gegen diese Aufgabe sperren könnte, so daß auch gegen ihn noch vorzugehen war (II, 7). Erkennbar wird nur das Endergebnis: Noch anderthalb Jahrhunderte nach Festlegung dieses Sondersendrechts waren jedenfalls unter den Slawen Relikte des alten Glaubens im Schwange, die Ärgernis erregten. ${ }^{63}$

Die Bedeutung der Quelle für die Entwicklung des kirchlichen Rechtes im Hoch - mittelalter bleibt unberührt. Beiläufig ergaben sich Aspekte zur slawischen Religions geschichte, die in ihrer Art gleichfalls einmalig sind. Sie wurden schon früher eingehend behandelt, ${ }^{64}$ daher hier nur kurz zur Erinnerung: Verfolgt wird „heidnisches“ Wesen unter Menschen, die dem Anspruch ausgesetzt sind, Christen zu sein (post perceptam baptismi

\footnotetext{
${ }^{61}$ Koeniger, Sendger. I, S. 104 u. ö.

${ }^{62}$ Druck: Th. Gousset, Les actes de la province ecclésiastique de Reims I, Reims 1862, S. 550-561; mit abweichender Kapitelzählung auch bei Mansi XVIII, S. 189-201. Auch dieser Text wird außerhalb der landesgeschichtlichen Forschung erstaunlich wenig beachtet. Für Hervé genüge hier der Hinweis auf M. Lauwers, 9. Hervé, in: Dict. d'hist. et de géographie ecclésiastiques XXIV (1993), Sp. 240-243, vgl. auch Schröder (wie Anm. 50), S. 157-160, 180-197, 208-212, vgl. 156, sowie M. Bur, in LMA IV (1989), Sp. 2157.

${ }^{63}$ Kahl 2004, S. 38-40.

${ }^{64}$ Kahl 2004, S. 33-40
} 
gratiam, sagt das Rubrum); dabei wird nicht mehr, wie in den älteren Würzburger Privi - legien über die Slawenkirchen, deren Errichtung Karl d. Gr. noch selbst verfügte, vom populus noviter conversus gesprochen, von einer gerade erst bekehrten Bevölkerung. ${ }^{65}$ Andererseits bleibt alles unbeleuchtet, was bereits im Sinn der Kirche abläuft, mag dies nun viel oder wenig sein. Für das vorchristliche Slawentum fällt wenig ab - vielleicht nur ein einziger Satz. Er bringt jedoch, so mager er ist, die wahrscheinlich wichtigste Aussage, die wir über den hier als trebo bezeichneten Opferbrauch besitzen. Ob in der Fortsetzung, die von Bestattungen bei oder in den hougir spricht, slawisches oder germanisches Brauchtum angesprochen ist oder beides vereint, bleibt offen.

\section{VI.}

Der Historiker ist gehalten, ehe er einen Vorschlag vertritt, nach möglichen Alter na - tiven Ausschau zu halten, um sich nicht voreilig festzulegen. Ich gestehe, daß das in diesem Fall nicht gelungen ist, weder für die Datierung noch für die Einordnung in historische Zusammenhänge. Das „Sondersendrecht für Nichtfranken“ bleibt für mich ein Würz - burger Text, und zwar ein solcher, der nicht allein die Entwicklung kirchlicher Rechts - setzungen berührt, sondern zugleich einen wichtigen Baustein liefert zur Beurteilung König Konrads I. und seines Bischofs Thiodo, ohne daß deren persönliche Anteile sich näher abgrenzen lassen.

Nebenergebnisse, die gestreift wurden, runden das Bild ab. Besonders hervorzuheben ist die prinzipielle Gleichbehandlung von Slawen und Nichtslawen. Die Bestimmungen mochten mit unterschiedlicher Häufigkeit einschlagen, je nach dem Stand der Christia - nisierung. Denen, die deutsche Mundarten sprachen, war kein „Götzenopfer" nach Art des trebo mehr anzulasten, sondern nur noch ein Bestattungsbrauch. Die prinzipielle Gleichbehandlung bleibt davon unberührt.

Abschließend ist noch vor einem Fehlschluß zu warnen. Sämtliche vorstehend herangezogenen Diplome Konrads I. sind von dem Mann rekognosziert, der seit 909 das Kanz leramt innehatte: Salomo III., Bischof von Konstanz und einflußreicher Ratgeber dieses Königs. Sein nomineller Amtssitz ist einer der beiden Orte, an denen für uns eine Version des Würzburger Sondersendrechts aufs Pergament kam. Man mag sich fragen, ob der Text durch diesen Mittelsmann dorthin gelangt war, doch er hat mit dem angesprochenen Überlieferungsstrang schwerlich etwas zu tun. Die Überlieferung im ursprünglich Konstanzer Codex (Abbildung), der jenes Sondersendrecht mit aufnahm, entpuppte sich ja, wie gezeigt, als ein Nachtrag, den der Schreiber nicht selbständig eingefügt hat, sondern bereits in seiner Vorlage fand. ${ }^{66}$ Die Provenienz dieser Vorlage kennen wir nicht; sie in Konstanz selbst zu suchen, weitab aller slawischen Probleme, die sich in diesem Sondersendrecht so stark in den Vordergrund drängen - dazu besteht kein Grund. Bischof Salomon wird bei den Beratungen und Be schlüssen, aus denen es hervorging, ähnlich beteiligt gewesen sein wie in Hohenaltheim - eine Aus fer - tigung mit heimzunehmen, hatte niemand Ursache, dessen ureigenste Angele genheiten da rin unberührt blieben. Für trebo und auch für hougir war am Bodensee kein Platz, und vollends mit seiner Zweiteilung der Laienwelt war der Text kaum verallgemeinerungsfähig. Ihn gleichwohl festzuhalten, muß-

\footnotetext{
${ }^{65}$ S. Anm. 13.

${ }^{66}$ Oben bei Anm. 11, Abb. unten S. (57).
} 
ur fux $\cdot$ fed poltmodüpprux Areleprur dirudicarara fynodo. seceptr; Lucuanur $\overrightarrow{p s}$ adruno papa iulso. receper dectam illur huer of olmmanupep $\vec{r}$ depo econciluatur $\vec{e}$ decete fuac. Sun i cuupdem eceté hrerofolimiane papa dommaxit . Q ipfe retú ocenaur papa fortinu d.mmun Ata in ppum reftrourt Fedem epm'a felice papa deminari: opolim - que duda palambru uocabaur Polued pur'ide urbe ancapriftena mufie in nucopolum

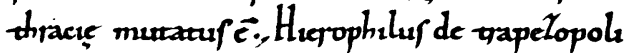
frifiae ranfingraure in platonopolim tracie..

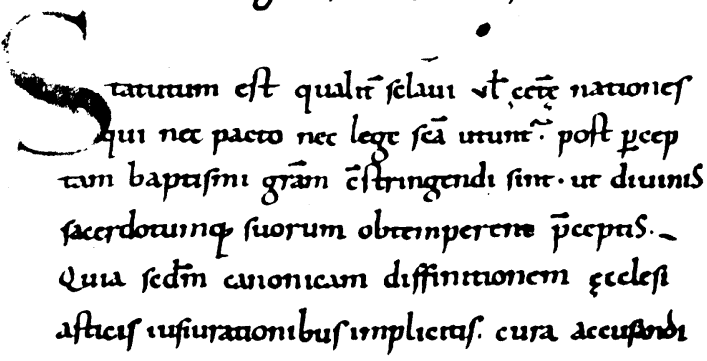

Universitätsbibliothek Eichstätt, Cod. st 772, fol. 23v, Ausschnitt. Die Abbildung zeigt, daß der Text des Würzburger Sondersendrechts, beginnend mit Statutum est, von gleicher Hand eingetragen ist wie der vorausgehende.

te man schon ein eingefleischter Sammler sein, der im Eifer einen Regino noch übertraf - ausgenommen vielleicht die Würzburger selbst. Die Be - schlüsse in der Mainmetropole auf freigebliebenen Spalten einer Canones-Sammlung einzutragen, als unmittelbar eigenes Diözesanrecht, das konnte naheliegen, und wer dann diesen Codex abschrieb (oder auch eins seiner Derivate), der nahm sie wie selbstverständlich mit. Vorlage war Vorlage - sie war so sorgfältig und vollständig zu kopieren, wie es nur anging.

Leider kennen wir keine Handschrift, an der diese Vermutung überprüft werden könnte, doch das spricht nicht gegen sie. Würzburg hat zahlreiche Dombrände erlebt, von anderem abgesehen. Niemand vermag zu überblicken, was alles bei solchen Katastrophen verlorenging. Daß es aber Verluste gab, wird niemand bezweifeln wollen. 


\section{Textedition und Verdeutschung}

\section{Das Würzburger Sondersendrecht für Nichtfranken}

\section{Überlieferung:}

1. Universitätsbibliothek Eichstätt, Staatsbestand (st) Nr. 772 (früher: Domarchiv, Ms. 6, aus Seminarbibliothek, Ms. 48), fol. 23 ${ }^{\text {vb }}$ bis fol. $24^{\text {rb }}$. Der Codex entstand um $1040 / 50$, vielleicht nicht in Eichstätt, doch jedenfalls in Bayern oder Franken. ${ }^{67}$ Im folgenden: E.

2. Universitätsbibliothek Freiburg i. Br., Hs. 7, fol. 48rb-49rb. Der Codex stammt aus der Dombibliothek Konstanz und kann im dortigen Skriptorium vor 1046 entstanden sein. ${ }^{68}$ Im folgenden: K.

\section{Bisherige Ausgaben:}

Der Text wurde 1837-1907 fünfmal ediert, doch nur einmal kritisch (nachstehend Nr. 4) und auch damals nicht nach den Ansprüchen, die heute gestellt werden müssen:

1. H. Amann, Praestantiorum aliquod Codicum MSS., qui Friburgi servantur, ad iurispru - dentiam spectantium notitia, fasc. II, Friburgiae Brisigaviae 1837, S. 63-65, aus K. - Im folgenden: A.

2. R. W. Dove, Untersuchungen über die Sendgerichte, in: Zschr. F. Deutsches Recht 19 (1859, S. 382-384, aus E.) Im folgenden nicht mehr zu berücksichtigen wegen Nr. 4.

3. J. Merkel, Lex Baiuvariorum, Add. XVII (MGH LL III, 1863, S. 486 f.) aus E. Im folgenden: $M$.

4. R. W. Dove, Das von mir sog. Sendrecht der Main- und Rednitzwenden, in: Zschr. f. Kirchenrecht 4 (1864), S. 160-162, aus K und E. Erste und bisher einzige kritische Ausgabe. Im folgenden: $\mathrm{D}$.

5. A. M. Koeniger, Die Sendgerichte in Deutschland I, München 1907, S. 194-195, nach 4., mit modernisierter Interpunktion, ohne Apparat.

Vorliegende Edition fußt auf E und K und kann dabei im wesentlichen dem von D hergestellten Text folgen. Neu im Druck kenntlich gemacht werden die mittlerweile nachgewiesenen Textparallelen, die m. E. als Abhängigkeiten des Würzburger Entwurfs zu verstehen sind, nämlich ein in der Collectio Catalaunensis fehlender angeblicher Kanon des Konzils von Tribur 895 (oben bei Anm. 5-6; im folgenden: T) und ein einem nicht datierbaren Konzil von Rouen zugeschriebener Kanon (oben bei Anm. 5 u. 7; im folgenden: R). Abweichungen der sonst bekannten Fassungen dieser mutmaßlichen Vorlagen werden in [] vermerkt. Der Variantenapparat von D wird um stereotype orthographische $\mathrm{Ab}$ - weichungen von $\mathrm{E}$ gegenüber $\mathrm{K}$ entlastet, die keine textkritische Bedeutung haben (z. B. konsequentes aecclesia statt ecclesia, ae statt oe oder $r r$ statt $r$ ). Die Interpunktion wird gleichfalls modernisiert, dazu zwecks leichterer Zitierbarkeit eine Kapitel- und Para - graphenzählung neu eingeführt, die in den Handschriften kein Vorbild hat. Den beiden beteiligten Universitätsbibliotheken sei für freundliche Zusammenarbeit, insbes. die Publikationsgenehmigung, gedankt, vor allem aber Herrn Prof. Dr. Theo KÖLZER, Bonn,

\footnotetext{
${ }^{67}$ H. Hoffmann, Buchkunst und Königtum im ottonischen und frühsalischen Reich, Stuttgart 1986, S. 208 f.; vgl. Hoffmann - Pokorny (wie Anm. 6), S. 129, vgl. 68 m. Anm. 23.

${ }^{68}$ Hoffmann - Pokorny, S. 129 u. 136-143.
} 
für zahlreiche Hinweise, ohne die die Bearbeitung des komplizierten Tex tes niemals so möglich geworden wäre. Der unvergeßliche Freiburger Kollege Prof. Dr. Hubert MORDEK, der dieses Vorhaben gleichfalls freundlich gefördert hat, kann den Dank leider nicht mehr entgegennehmen $(\dagger$ 17. 3. 2006).

\section{Textedition}

Statutum est qualiter Sclaui uel ${ }^{\mathrm{a}}$ ceterae nationes, qui nec pacto nec lege Salica ${ }^{\mathrm{b}}$ utuntur, post perceptam baptismi gratiam constringendi sint, ut divinis sacerdotumque suorum obtemperent praeceptis.

Aus T $(I, 1) \quad$ Quia secundum canonicam diffinitionem ecclesiasticis iusiurationibus implicitis cura accusandi proclamandique scelera committitur, quae infra omnem

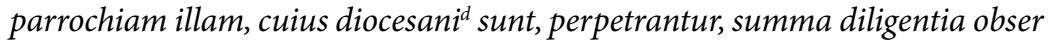
uandum est, ut nullus diuinae legis transgressor, licet alterius conditionis uel parrochiae sit, in synodica stipulatione reticeatur.

Aus R (2) Quodsi quis, cuiuscumque sit gentis, nationis uel linguae, contempto dei omnipotentis timore ita inreuerens deprehensus fuerit post huiusmodi sacramentum, ut iurata per quodcunque ingenium siue excusationem aut dissimulationem noticiae uiolare praesumat, a cuiuscunque nationis uel linguae uiris nobilibus tantum ${ }^{f}$ et numero testimonio congruentibus periurii uel alicuius criminis impetitus fuerit noxae $e^{g}$ penitus quida unius legis et gentis ${ }^{h}$ non sunt ${ }^{i}$ obiectione remota, aut uindictae ${ }^{k}$ periurii subiaceat aut se exl impetita suspitione igniti ferri iudicio expurget.

(3) Quodsi ${ }^{m}$ temeritatis obstinatia ${ }^{n}$ in neutro sanctae dei ecclesiae satisfacere uolue -rit, a liminibus et communione eiusdem sanctae deip ecclesiae habeatur disclusus ${ }^{q}$ et exlex, quousque resipiscendo canonicis obtemperauerit institutis ${ }^{r}$.

\footnotetext{
a A fälschlich et

b K. - E: scă (= sancta), dazu D, S. 160,10.

c [T: et proclamandi]

d K. - E.: diocaesanei

e K. - E: omnipotentis dei

f [R: tantum nobilibus]

g E: fuerit. noxae. - KD: noxa

h K. - E: gentis et legis

K. - E: cn ft; M: censentur

k [R. uindicta]

1 E.- ex fehlt in $\mathrm{K}$

m [R: quod si quis]

n K. - E: obstinantia

- $[a$ fehlt in R]

p K. dei fehlt in E.

q [R: exclusus]

r [R: statutis]
} 
(II, 1) Praeterea festiuitates dominicas ceteraques anni solemnitate obseruandas $^{\mathrm{s}}$ in parrochiali ecclesia a sacerdote indictas, quicunque aliquo opere temerare praesumpserit uel quicquid tunc laborare praeter id, quod ad domesticum apparatum eiusdem diei indiget,

- uel qui legitima ieiunia, hoc est quadragesimam et IV tempora et uigilias esu carnium contaminauerit,

- aut quit idolothita, quod trebo dicitur, uel obtulerit aut manducauerit,

- aut qui mortuos non in atrio ecclesiae, sed ad tumulos, quos ${ }^{\mathrm{u}}$ dicimus more gentilium hougir, sepelierit,

- aut decimas dare noluerit,

- aut qui a sacerdote in ecclesia bannitus fuerit ad placitum episcopi siue archipresbyteri et uenire contempserit, canonicis induciis sacerdos eum pro huiusmodi praeuaricatione et neglegentia ad poenitudinem inuitet.

(2) Quod si contempserit, exactor publicus, id est ${ }^{v}$ centurio aut suus uicarius cum sacerdote pergat ad domun huiusmodi praesumptoris et de sua facultate tanti aliquid precii, bouem siue aliud aliquid ${ }^{\mathrm{w}}$ tollat, propter quod proteruus constringatur, ut humiliatus a sua prauitate resipiscat.

(3) Quod ipsum in ecclesiastica sacerdotis potestate locatum maneat, ${ }^{\mathrm{x}}$ donec transgressor $^{y} \mathrm{ab}$ inculcato ${ }^{z}$ crimine aut expurgando aut poenitendo satisfaciat.

(4) Quodsi infra spacium unius septimanae ita resipuerit, sibi sublatam recipiat suppellectilem; si vero ad finitas ${ }^{\text {aa }}$ inducias contumax venire distulerit, etiamsi postmodum poenitentiae se subdiderit, propter neglectas autem inducias $^{\text {bb }}$ sit in arbitrio sacerdotis, depositum in ecclesiasticos usus seruare aut repetenti condonare.

(5) Quod si quispiam tam male pertinax invenitur, ut nec omnipotentis dei territus timore nec iactura uel opum damno attenuatus ab huiusmodi sceleris obstinatia ad resi piscendum coerceri possit, deretum est ab ecclesia

S. E: aliaque

t K. E: quisquis

" KEADKö: quod. Sowohl tumulos wie hougir erfordern die obige Relativpartikel oder eine angemessene Entsprechung. Der K und E gemeinsame offensichtliche Fehler unterstreicht die Abhängigkeit beider Codices von gemeinsamer Vorlage.

v AM: KE: iđ, Kö: i.e.

w K. E: aut aliquid aliud

$x$ K. E: maneat locatum

y E. - K: transgresor

z E. - K. inconculcato. - A. inculpato

aа K. - E. diffinitias

${ }^{\mathrm{b}}$ K. - E. indutias 
exclusum humana priuari com munione, et tunc demum, si sit fiscalinus colonus omnia quaecunque possidet a rei publicae ministro ${ }^{c c}$ infiscentur et in dominicam redigantur potestatem.

(6) Si quis autem in suo uel in alterius praedio ita scelerosus exstiterit, simili modo cum centurione dominus eiusdem praedii, quaecunque habuerit, ab illo auferat suaeque uendicet potestati.

(7) Si uero ipse centurio aut dominus hoc agere neglexerit, sit ipse, quod est ${ }^{\mathrm{dd}}$, quem rebus foueat et tuetur, excommunicatus, et tamen nihilominus per ducem aut ${ }^{\mathrm{ee}}$ comitem expulsus, illius infiscentur substantiae.

\section{Verdeutschung}

Es ist festgesetzt worden, wie die Slawen (oder Wenden) und sonstigen Rechtsgruppen, ${ }^{69}$ die weder nach dem Pactus $^{70}$ noch nach dem salischen Gesetz leben, im Zaum zu halten sind, daß sie den göttlichen Geboten und (den Vorschriften) ihrer Priester gehorchen.

(I, 1) Laut kanonischer Satzung wird kirchlich vereidigten (Personen) die Aufgabe anvertraut, Verbrechen anzuklagen und bekanntzumachen, welche innerhalb des gesamten Sprengels verübt werden, dem sie als Diözesanen angehören. Deshalb ist mit höchster Sorgfalt darüber zu wachen, daß kein Übertreter des göttlichen Gesetzes, selbst wenn er einem anderen Stande oder Sprengel angehört, im Sendverfahren verschwiegen wird.

(2) Wenn also jemand, welchem Volksstamm, welcher Rechtsgemeinschaft ${ }^{71}$ oder Sprache immer er angehört, die Furcht vor dem allmächtigen Gott verachtet und dermaßen ohne Ehrfurcht befunden wird nach dieser Eidesleistung, daß er, was geschworen, durch irgendeine Eingebung, Entschuldigung oder wider besseres Wissen ${ }^{72}$ zu verletzen sich erdreistet, (der) soll, wenn er von Männern beliebiger Rechts- und Sprach zuge hörigkeit, nur von Adel und in der Zeu genschaft angemessener Zahl, belastet wird, des Meineides oder eines anderen Verbrechens ${ }^{73}$ schuldig sein unter völligem ${ }^{74}$

${ }^{c} \mathrm{E}:$ rei publicae ministerio. - K: rei publicae ministro.

dd K. - quidem E.

ee A fälschlich: et.

${ }^{69}$ Zum Sprachgebrauch: Kahl 2004, S. 25 f. mit 31; vgl. nachstehend Anm. 71.

${ }^{70}$ Dazu Kahl 2004, S. 27 f.

${ }^{71}$ Da gentis im Text selbständiger Zusatz zur Vorlage R ist, muß es den Redaktoren auf stärkere Betonung einer Differenzierung angekommen sein. Offenbar ging es um den Unterschied zwischen Abstammungs- und Rechtszusammenhang. Nur der zweite war in nationes ihres Sprach - gebrauchs erfaßt. Es ist beachtlich, daß beides nicht mehr als identisch empfunden wurde.

${ }^{72}$ Wörtlich: durch Verhehlung von Kenntnis.

${ }^{73}$ Auffälliger Zusatz zur Vorlage, nachdem es im Zusammenhang um nichts geht als um die Wahrung des Eides, mit dem sich die Send- oder Rügezeugen zu verpflichten hatten. Im folgenden nicht erneuert.

${ }^{74}$ Auch penitus ist Zusatz zur Vorlage. Man meint zu spüren, wie es den Redaktoren auf verstärkten Nachdruck ankam. 
Ausschluß des Einspruchs, sie seien nicht gleicher Rechts- und Abstammungsgemeinschaft. (Er soll dann) entweder der Strafe für Meineid unterliegen oder sich von dem angelasteten Ver dacht durch die Probe des glühenden Eisens reinigen.

(3) Wenn er aber in verwegener Hartnäckigkeit weder auf die eine noch die andere Weise der Kirche Gottes Genugtuung leisten will, dann werde er von der Schwelle und aus der Gemeinschaft ebendieser Heiligen Kirche Gottes ausgeschlossen und für friedlos erachtet, bis er einlenkt und den kanonischen Bestimmungen gehorcht.

(II, 1) Im übrigen (sind) die Sonntage und sonstige Festtage des Jahres, wenn sie in der Pfarrkirche vom Priester angesagt worden sind, einzuhalten. Wer sich herausnimmt, (sie) durch irgendeine Arbeit zu schänden oder dann irgend etwas zu verrichten über das hinaus, was für den Haushalt des betreffenden Tages nötig ist,

- oder wer die gesetzlichen Fasten, das heißt Quadragesima und Quatem ber und die (jeweiligen) Vigilien mit Fleischgenuß befleckt,

- oder wer die Götzenopfer, was man „trebo“ nennt, entweder darbringt oder ißt,

- oder wer Tote nicht auf dem Friedhof einer Kirche bestattet, sondern bei (oder: in) den Hügeln, die wir nach der Weise der Heiden ${ }^{75}$ „hougir“ nennen,

- oder (wer) die Zehnten ${ }^{76}$ nicht geben will,

- oder wer vom Priester in der Kirche vor das Gericht des Bischofs oder des Erzpriesters geladen wird und zu kommen verschmäht: mittels der kanonischen Fristen soll der Priester ihn für solcherart Anmaßung und Nachlässigkeit zur Buße auffordern.

(2) Wenn er sich darüber hinwegsetzt, soll der öffentliche Vollzugsbeauftragte, d. h. der Zentgraf (hunno) oder sein Vertreter, mit dem Priester sich zum Hause des solchermaßen Widersetzlichen begeben und von dessen Vermögen etwas nehmen von solchem Wert - ein Rind oder irgend etwas anderes

${ }^{75} \mathrm{Zu}$ gentiles „Heiden“: A. Dove, Studien zur Vorgesch. d. deutschen Volksnamens, in: Sitzungsber. d. Heidelberger Akad. d. Wiss., phil.-hist. Kl. 1916/8, bes. S. 52-56. Die Wortverbindung more gentilium z. B. in c. 19 der von päpstlichen Legaten zusammengestellten capitula, die angelsächsische Synoden 786 anzunehmen hatten, vgl. MGH EE IV, S. 27. Im vorliegenden Text zeigt die Wendung, daß ahd. houc für den Textredaktor zu den mit heidnischer Qualität aufgeladenen Ausdrücken gehörte, die ein Christ eigentlich zu meiden hatte.

${ }^{76}$ Es ist zu beachten, daß hier ganz allgemein von decimae gesprochen wird, ohne Abhebung einer besonderen decima constituta oder eines speziellen „Slawenzehnten“. Ob der allgemeine Ausdruck unterschiedliche Leistungen unterschiedlicher Bevölkerungsgruppen gemeinsam abdecken soll oder eine einheitliche Belastung aller voraussetzt, muß wohl offenbleiben. 
-, um dessentwillen der Aufsässige sich zügeln mag, daß er sich demütigt und von seiner Verworfenheit wieder zur Besinnung kommt.

(3) Dieses Stück soll in der kirchlichen Gewalt des Priesters verbleiben, bis der Übertreter für das (ihm) angelastete Verbrechen entweder, indem er sich reinigt, oder durch Buße Genugtuung leistet.

(4) Wenn er binnen einer Woche so Vernunft annimmt, empfange er das ihm entzogene Stück seiner Fahrhabe zurück; wenn er aber bis zum Ablauf der Frist in Trotz zu kommen zögert, dann soll es, auch wenn er sich später der Pönitenz unterwirft, wegen der Fristversäumnis im Belieben des Priesters stehen, das Verwahrstück für kirchlichen Gebrauch einzubehalten oder ihm auf seine Bitten zurückzugeben.

(5) Wenn aber jemand dermaßen übel hartnäckig befunden wird, daß er weder durch die Furcht vor dem allmächtigen Gott noch durch Verlust und Vermö - gens schaden nachgiebig gemacht genötigt werden kann, aus der Verstocktheit eines solchen Verbrechens Vernunft anzunehmen, (so) ist verfügt, (ihm) als von der Kirche Ausgeschlossenem die menschliche Gemeinschaft zu nehmen, und dann soll schließlich, wenn er ein Bauer auf Staatsgut ist, alles, was er irgend besitzt, vom Vertreter der öffentlichen Gewalt eingezogen und wieder als Frongut verfügbar gemacht werden.

(6) Wenn aber jemand auf seinem Eigen oder auf dem Gut eines anderen mit solchem Frevel befleckt sitzt ${ }^{77}$, so soll ähnlich mit dem Zentgrafen der Herr eben dieses Gutes, was immer er besitzt, ihm abnehmen und in seine eigene Gewalt übernehmen.

(7) Wenn aber der Zentgraf selbst oder der Grundherr so zu verfahren versäumt, sei er selbst, was (der) ist, den er in der Habe begünstigt und schützt, (nämlich) exkommuniziert, und gleichwohl soll jener durch den Herzog ${ }^{78}$ oder den Grafen vertrieben und sein Vermögen eingezogen werden.

\footnotetext{
${ }_{77}$ D. h. als Hintersasse eines Privaten, weder auf Fron- noch auf Kirchengut.

${ }^{78}$ Zum dux s. oben bei Anm. 17-18 sowie Anm. 36.
} 


\title{
Würzburško pravo posebnih odposlancev za pokristjanjene Slovane in druge Nefranke. Pravno besedilo iz časa kralja Konrada I (918?). Uvod, edicija in nemški prevod
}

\author{
Hans-Dietrich Kahl
}

Avtor je vir provizorično obravnaval že leta 2004 v Studii mythologici Slavici 7. Tokrat ga objavlja skupaj z nemškim prevodom. Njegov nastanek pripisuje času kralja Konrada I (918?). Besedilo je bilo sprejeto očitno v Würzburgu v prisotnosti vladarja. Skupaj s sinodama v Triburju (859) in Hohenaltheimu (916) predstavlja poznokarolinško tendenco, da bi si s Cerkvijo zagotovili oblast, v danem primeru na območju, ki je imelo zelo velik delež slovanskega prebivalstva. Besedilo poudarja obred »trebo«. Jasno so razpoznavne vsebinske primerjave $\mathrm{z}$ drugimi cerkvenimi pravnimi besedili. 